\title{
XVI FÓRUM DE
}

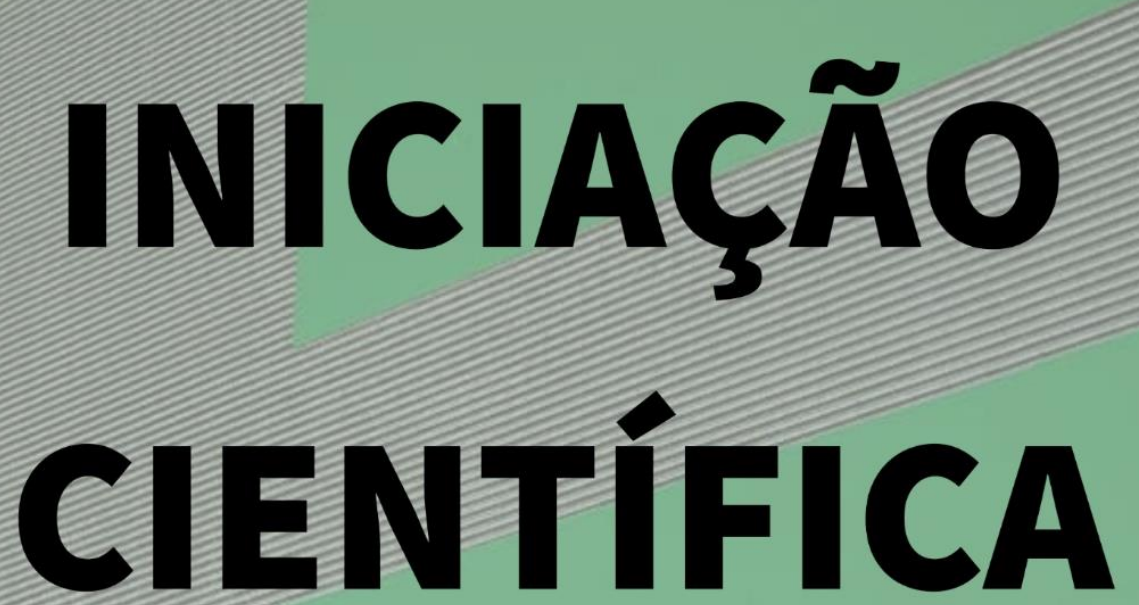

PIBIC-FMJ-CNPQ 2019-2020

FACULDADE DE MEDICINA DE JUNDIAÍ

R. FRANCISCO TELES, 250 - VILA ARENS, JUNDIAI - SP - CEP: $13202-550$ FONE: [11] $3395-2100$ 
FACULDADE DE MEDICINA DE JUNDIAÍ (FMJ)

PROGRAMA INSTITUCIONAL DE BOLSAS DE INICIAÇÃO CIENTÍFICA (PIBIC)

CONSELHO NACIONAL DE DESENVOLVIMENTO CIENTÍFICO E TECNOLÓGICO (CNPq)

XVI FÓRUM DE INICIAÇÃO CIENTÍFICA E PÓS-GRADUAÇÃO

AVALIAÇÃO DO PROGRAMA 2019/2020
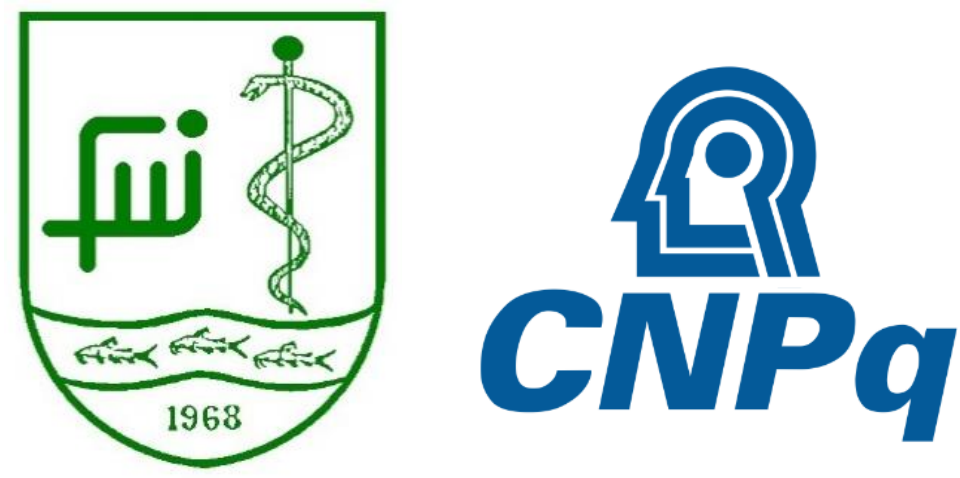

$10.29327 / 125370.16$

A Faculdade de Medina de Jundiaí realizará no dia 18 de setembro de 2020, sextafeira, o XVI Fórum de Iniciação Científica PIBIC-FMJ-CNPq. Devido à pandemia do novo coronavírus e à necessidade de distanciamento social, este ano o evento será realizado on-line, através de videoconferências no Google Meet.

Voltado aos alunos e professores dos cursos de Graduação e Pós-Graduação da FMJ, o evento tem como objetivo reunir a comunidade acadêmica da Faculdade para a apresentação dos trabalhos de Iniciação Científica, pertinentes à vigência 2019/2020. A organização do evento é de responsabilidade do Comitê Institucional de Pesquisa Científica - CIP da FMJ.

\section{DESCRIÇÃO DO EVENTO}

Público-alvo: Acadêmicos da Graduação, Alunos da Pós-Graduação, Professores e Orientadores de Pesquisa da FMJ.

Objetivo: Reunir a comunidade acadêmica da FMJ para apresentação dos Trabalhos de Iniciação Científica pertinentes ao Programa de 2019/2020.

Local e data: Google Meet da Faculdade de Medicina de Jundiaí, 18 de setembro de 2020. 


\section{PROGRAMA}

\section{DIRETORIA da FMJ}

Prof. Dr. EVALDO MARCHI - Diretor

Profa. Dra. ANA CAROLINA MARCHESINI DE CAMARGO - Vice-Diretora

\section{Membros do Comitê Externo Convidados}

- Profa. Dra. Carolina de Souza Machado - Professora Adjunta da Escola de Enfermagem da Universidade Federal da Bahia.

- Profa. Dra. Jamille Souza Fernandes - Professora Adjunta de Imunologia da Universidade Federal do Oeste da Bahia.

- Profa. Dra. Juliana Franceschini Pereira - Coordenadora de Pesquisa da Fundação ProAR.

- Profa. Dra. Simone Dal Corso - Professora Adjunta do Curso de Fisioterapia da Universidade UNINOVE.

Membros do Comitê Institucional de Pesquisa - CIP

- Prof. Dr. Eduardo Vieira Ponte - Coordenador do PIBIC e Professor Adjunto de Propedêutica.

- Profa. Dra. Alcione Vendramin Gatti - Vice-Coordenadora do PIBIC e Professora Adjunta da Disciplina de Parasitologia.

- Profa. Dra. Ana Lúcia Granja Scarabel Nogueira Carrasco - Professora Assistente da Disciplina de Cirurgia Pediátrica.

- Profa. Dra. Ivani Aparecida de Souza - Professora Adjunta da Disciplina de Fisiologia.

- Prof. Dr. Rodrigo Paupério Soares de Camargo - Professor Adjunto da Disciplina de Obstetrícia.

\section{AVALIAÇÃO DOS TRABALHOS}

\section{SALA 1}

Comissão Externa: Profa. Dra. Carolina de Souza Machado

Comitê Institucional: Prof. Dr. Eduardo Vieira Ponte

Abertura da sala virtual: 8:40 horas

Início da atividade: 9:00 horas

\section{SALA 2}

Comissão Externa: Profa. Dra. Jamille Souza Fernandes

Comitê Institucional: Profa. Dra. Ana Lúcia Granja Scarabel Nogueira Carrasco

Abertura da sala virtual: 9:40 horas

Início da atividade: 10:00 horas

\section{SALA 3}

Comissão Externa: Profa. Dra. Simone Dal Corso

Comitê Institucional: Profa. Dra. Ivani Aparecida de Souza

Abertura da sala virtual: 8:40 horas

Início da atividade: 9:00 horas

\section{SALA 4}

Comissão Externa: Profa. Dra. Juliana Franceschini Pereira

Comitê Institucional: Profa. Dra. Alcione Vendramin Gatti

Abertura da sala virtual: 13:40 horas

Início da atividade: 14:00 horas 


\section{SOBRE OS CONVIDADOS:}

Fonte: Currículo Lattes.

\section{Profa. Dra. Carolina de Souza Machado - Lattes (}

Possui graduação em Bacharelado em Enfermagem pela Universidade Católica do Salvador (2002). MBA Executivo em Saúde pela UCB e Atualiza; Mestrado e doutorado em Medicina e Saúde pela UFBA. Atualmente é professora adjunta da Escola de Enfermagem da UFBA; Exerce o cargo de Direção da Unidade (2017-2021) e é docente permanente do Programa de pós-graduação em Enfermagem (PGEnf- UFBA) e do Programa de Pós-graduação em Medicina e Saúde (PPGMS- UFBA). Tem experiência na área de clínica médica, epidemiologia e gestão de saúde, com ênfase em gestão hospitalar. Atua principalmente nos seguintes temas: asma, enfermagem, controle, programa e doenças respiratórias.

\section{Profa. Dra. Jamille Souza Fernandes - Lattes}

Professora adjunta da Universidade Federal do Oeste da Bahia - UFOB. Possui graduação em Biomedicina pela Universidade Estadual de Santa Cruz - UESC (2011). Mestrado (2013) e Doutorado (2017) em Imunologia pela Universidade Federal da Bahia - UFBA. Pósdoutorado (2017 e 2019) pela UFBA. Pesquisadora colaboradora do Núcleo de Excelência em Asma - NEA - UFBA. Tem experiência na resposta imune da esquistossomose e asma.

\section{Profa. Dra. Juliana Franceschini Pereira - Lattes 9}

Possui graduação em Fisioterapia pela Pontifícia Universidade Católica de Campinas (1997), Mestrado (2002) e Doutorado (2010) em Ciências pela Universidade Federal de São Paulo. Tem experiência na área de docência do ensino superior, tendo atuado como docente em universidades privadas por aproximadamente 20 anos, nas áreas de fisioterapia respiratória, oncologia e pesquisa científica. Atuou também na gestão educacional, na área de relações internacionais. Atualmente é líder de projetos na Fundação ProAR e coordenadora de pesquisa da iniciativa ProPulmão, da SDS Healthline/Instituto Tórax.

\section{Profa. Dra. Simone Dal Corso - Lattes}

Possui graduação em Fisioterapia pelo Centro Universitário do Instituto Porto Alegre (1989), Doutorado em Ciências (Reabilitação) pela Universidade Federal de São Paulo (2000) e Posdoutorado pela Universidade Federal de São Paulo (2002-2005) com período sanduíche na Katholieke Universiteit Leuven, Bélgica. Durante o Doutorado foi bolsista da CAPES e durante o Pós-doutorado foi bolsista da Fundação de Amparo à Pesquisa de São Paulo (FAPESP). Logo após o término de seu pós-doutorado, iniciou sua carreira como docente na Universidade Nove de Julho (UNINOVE) (2005), atuando como professora da graduação no curso de Fisioterapia ministrando disciplinas como cinesiologia, fisioterapia pneumológica, fisioterapia cardiológica e fisiologia do exercício, também atuando como supervisora de estágio no Ambulatório Integrado da Saúde (Unidade Memorial). Em 2015, passou a fazer parte do corpo docente do curso de graduação da Medicina, ministrando a disciplina de Bases Morfofuncionais 2 até 2020. Foi facilitadora da referida disciplina por dois anos. Atualmente é membro do Comitê de Ética em Pesquisa em Humanos. É professora do Programa de Pósgraduação em Ciências da Reabilitação da Universidade Nove de Julho - SP (2007), orientando mestrado e doutorado e Professora do Lato Sensu em Fisioterapia Cardiorrespiratória. É bolsista de produtividade em pesquisa do Conselho Nacional de Desenvolvimento Científico e Tecnológico (CNPq). Tem experiência na área de Fisioterapia, atuando principalmente nos seguintes temas: fisioterapia cardiorrespiratória, função pulmonar, fisiologia clínica do exercício, reabilitação pulmonar, avaliação da fadiga muscular periférica e testes de capacidade funcional na saúde e nas doenças cardiorrespiratórias. 


\section{RESUMOS DO PIBIC-FMJ-CNPq 2019/2020}

A INFLUÊNCIA DA ATIVIDADE FÍSICA NO PERFIL CLÍNICO DE PACIENTES DIABÉTICOS DO TIPO 2.

ANÁLISE DAS CONCENTRAÇÕES DA AMILASE SALIVAR E CORRELAÇÕES COM A SÍNDROME DE OVERTRAINING E LESÕES ESPORTIVAS, EM ATLETAS PROFISSIONAIS DE FUTEBOL

ANÁLISE DE DIÁRIOS ALIMENTARES DE ALUNOS DA REDE PÚBLICA DE JUNDIAÍ ANTES E APÓS PALESTRA EDUCATIVA SOBRE NUTRIÇÃO E SAÚDE HUMANA.

ANÁLISE DO REPARO ÓSSEO ENXERTADO COM SELANTE DE FIBRINA DERIVADO DO VENENO DE CASCAVEL

AVALIAÇÃO CLÍNICA E ESTRATIFICAÇÃO DE RISCO NO CARCINOMA BEM DIFERENCIADO DA TIREOIDE: ANÁLISE DE DUAS COORTES LONGITUDINAIS E RETROSPECTIVAS 1961 a 1992 e 1993 a 2018.

AVALIAÇÃO DA ADESÃO AO TRATAMENTO DE HIPERTENSÃO ARTERIAL SISTÊMICA AVALIAÇÃO DA PERCEPÇÃO DE HIGIENE ORAL NO DESENVOLVIMENTO DE CARCINOMA ESPINOCELULAR DE CAVIDADE ORAL.

AVALIAÇÃO DA PERCEPÇÃO E CONHECIMENTO DE ONCOLOGISTAS BRASILEIROS SOBRE EPIGENÉTICA

AVALIAÇÃO DA PERCEPÇÃO E CONHECIMENTO DE PSIQUIATRAS SOBRE

FARMACOGENÉTICA.

AVALIAÇÃO DA PREVALÊNCIA DE SÍNDROME DO ANTICORPO ANTIFOSFOLÍPIDE NOS PACIENTES DAS DISCIPLINAS DE HEMATOLOGIA E REUMATOLOGIA DO AMBULATÓRIO DE ESPECIALIDADES DA FACULDADE DE MEDICINA DE JUNDIAÍ E DO AMBULATÓRIO DE PRÉNATAL - SAÚDE DA MULHER/PMJ

AVALIAÇÃO DA PREVALÊNCIA DE TABAGISMO EM ADOLESCENTES RESIDENTES NO MUNICÍPIO DE JUNDIAÍ

AVALIAÇÃO DA RELAÇÃO DE INDICADORES SOCIOECONÔMICOS COM O ÍNDICE DE ESTRESSE PERCEBIDO E QUALIDADE DE VIDA EM ESTUDANTES PRÉ-VESTIBULARES........12

AVALIAÇÃO DO EFEITO DO TRATAMENTO COMBINADO COM METFORMINA E SINVASTATINA SOBRE A RESPOSTA INFLAMATÓRIA DE MACRÓFAGOS ESTIMULADOS COM CRISTAIS DE COLESTEROL

AVALIAÇÃO DO PAPEL DA HEPARANASE-1 (HPSE-1) PRODUZIDA POR CÉLULAS TUMORAIS PROSTÁTICAS NA DIFERENCIAÇÃO E POLARIZAÇÃO DOS MONÓCITOS HUMANOS (THP-1) EM MACRÓFAGOS

AVALIAÇÃO DOS EFEITOS DA METFORMINA SOBRE A RESPOSTA INFLAMATÓRIA DE CÉLULAS MONONUCLEARES DO SANGUE PERIFÉRICO E NEUTRÓFILOS DE INDIVÍDUOS COM ARTRITE PSORIÁSICA.

AVALIAÇÃO DOS EFEITOS DA PREGABALINA NA PROLIFERAÇÃO E INVASIVIDADE DA LINHAGEM CELULAR DE CÂNCER DE PRÓSTATA (LNCaP).

AVALIAÇÃO DOS EFEITOS DE COMPONENTES DE BIOFILME FORMADO POR CANDIDA ALBICANS SOBRE AS FUNÇÕES EFETORAS DE NEUTRÓFILOS E MACRÓFAGOS.

CARACTERÍSTICAS CLÍNICAS DAS QUEDAS EM IDOSOS FRÁGEIS INTERNADOS EM ENFERMARIA DE PSICOGERIATRIA

CONSTELAÇÃO FAMILIAR: A NOVA PIC DO SUS NAS UNIDADES DE SAÚDE EM JUNDIAÍ.....19 DIABETES MELLITUS TIPO 2: DETERMINANTES SOCIAIS NA ADESÃO AO AUTOCUIDADO EM IDOSOS 
DOENÇAS DERMATOLÓGICAS PREVALENTES EM UM HOSPITAL INFANTIL DA REDE PÚBLICA DE SÃO PAULO

EPIDEMIOLOGIA DA FEBRE MACULOSA NA REGIÃO METROPOLITANA DE JUNDIAÍ, NO ESTADO DE SÃO PAULO E NO BRASIL.

EPIDEMIOLOGIA DOS ACIDENTES COM ANIMAIS PEÇONHENTOS NO ESTADO DE SÃO

PAULO E NO MUNICÍPIO DE JUNDIAÍ

ESTUDO COMPARATIVO ENTRE OS EFEITOS DAS ENTEROTOXINAS ESTAFILOCÓCICAS E DO LIPOLISSACARIDEO DE ESCHERICHIA COLISOBRE AS PROPRIEDADES FUNCIONAIS DE NEUTRÓFILOS

ESTUDO DA UTILIZAÇÃO DE MATRIZES DE COLÁGENO e ELASTINA ASSOCIADO COM NANOHIDROXIAPATITA NO REPARO ÓSSEO

ESTUDO DO EFEITO DO EXTRATO POLYPODIUM LEUCOTOMOS SOBRE AS VIAS DE RESPOSTA IMUNE EM LINHAGEM HUMANA DE MACRÓFAGOS.

ESTUDO IN VIVO DA APLICABILIDADE DE MATRIZES POLIMÉRICAS DE POLI (ECAPROLACTONA) E POLI (HIDROXIBUTIRATO-CO-HIDROXIVALERATO) NO REPARO DE LESÕES CRANIANA

FLUXOGRAMA PARA ATENDIMENTO DE URGÊNCIAS E EMERGÊNCIAS EM CRISES

FALCIFORMES NO HOSPITAL UNIVERSITÁRIO DE JUNDIAÍ

HISTÓRIAS DE VIDA E DESENVOLVIMENTO DE ENDOMETRIOSE

HUMANIZAÇÃO DE UM AMBULATÓRIO MÉDICO DA CIDADE DE JUNDIAÍ: LEVANTAMENTO DOS INDICADORES DE AVALIAÇÃO EM SAÚDE.

INVESTIGAÇÃO DE ENTEROPARASITOSES EM CRIANÇAS ATENDIDAS NA UNIDADE DE SAÚDE DA FAMÍLIA VILA ANA, JUNDIAÍ-SP, NO PERÍODO DE 2019

LITERACIA EM SAÚDE EM ADULTOS DIABÉTICOS USUÁRIOS DO SERVIÇO PÚBLICO DE SAÚDE EM MUNICÍPIOS DE SÃO PAULO

METODOS CONTRACEPTIVOS REVERSÍVEIS DE LONGA DURAÇÃO EM MULHERES ADOLESCENTES: SATISFAÇÃO NO USO, PADRÃO MENSTRUAL E MODIFICAÇÕES NA FLORA VAGINAL

O PAPEL DA VIA DE SINALIZAÇÃO DA FOSFATIDILINOSITOL-3-QUINASE (PI3K) NOS EFEITOS INIBITÓRIOS DAS ENTEROTOXINAS ESTAFILOCÓCICAS DO TIPO A (SEA) E B (SEB) SOBRE AS PROPRIEDADES FUNCIONAIS DE NEUTRÓFILOS

O PAPEL DA VIA DE SINALIZAÇÃO DA p38 MAPK NA DISFUNÇÃO DE NEUTRÓFILOS PRODUZIDA PELAS ENTEROTOXINAS ESTAFILOCÓCICAS DO TIPO A (SEA) E B (SEB) ..........36 PERFIL EPIDEMIOLÓGICO DA POPULAÇÃO ADULTA ATENDIDA PELO PROJETO VOZES DAS RUAS EM JUNDIAÍ.

PERFIL EPIDEMIOLÓGICO DE CÂNCER GINECOLÓGICO NO SISTEMA ÚNICO DE SAÚDE DE JUNDIAÍ.

PIC: DISTRIBUIÇÃO TERRITORIAL E DEMANDA NAS UNIDADES DE SAÚDE DE JUNDIAÍ ........39 PREFERÊNCIAS DOS PAIS NA PARTICIPAÇÃO DA ANESTESIA DE SEUS FILHO ….....................40 PREVALÊNCIA DE TRANSTORNOS MENTAIS COMUNS EM ESTUDANTES DE MEDICINA E SUA ASSOCIAÇÃO COM QUALIDADE DE VIDA E EMPATIA, UM ESTUDO PROSPECTIVO .........41 SOROPREVALÊNCIA DA RUBÉOLA EM GESTANTES DE ALTO RISCO DA COORTE ZIKA JUNDIAÍ E ASSOCIAÇÃO COM A MICROCEFALIA

DESCOBERTA PRÉ-CLÍNICA E DESENVOLVIMENTO DA MILTEFOSINA ORAL PARA O TRATAMENTO DA LEISHMANIOSE VISCERAL

UTILIZAÇÃO DE MEMBRANA DE QUITOSANA E NANOTUBOS DE CARBONO ASSOCIADOS A LASERTERAPIA PARA O TRATAMENTO DE LESÕES ÓSSEAS EM FÊMUR DE RATOS 


\title{
A INFLUÊNCIA DA ATIVIDADE FÍSICA NO PERFIL CLÍNICO DE PACIENTES DIABÉTICOS DO TIPO 2
}

\author{
LUIZ, V.F. ${ }^{1}$, OLIVEIRA, A2 ${ }^{2}$ LOPES-SANTO L², de AZEVEDO, D.D.T², AUGUSTO, T.M. ${ }^{2,3}$; \\ CERVIGNE, N.K ${ }^{2,3}$.
}

1. Graduando do curso de Medicina; Faculdade de Medicina de Jundiaí

2. Laboratório de Biologia Molecular e Cultura Celular (LBMCC), Departamento de Morfologia e Patologia Básica, Faculdade de Medicina de Jundiaí, Jundiaí, SP.

3. Professora Adjunta do Departamento de Clínica Médica da Faculdade de Medicina de Jundiaí (FMJ), Jundiaí/SP.

\section{Endereço para correspondência:}

Nome do autor: Prof. Dr. Nilva K. Cervigne Furlan, MSc, PhD: Rua Francisco Telles, 250, Vila Arens II, Jundiaí, SP - Brasil. Telefone: (11) 3395-2100 ext. 2137. E-mail: nilva.cervigne@gmail.com

\section{RESUMO:}

Introdução: O diabetes mellitus (DM) é uma das doenças crônicas priorizadas em nível global. Sua prevalência causa importante morbidade devido a complicações agudas e crônicas, gerando significativos danos econômicos e sociais. No Brasil, é considerado um grande problema de saúde pública, sendo responsável por quase $8 \%$ de mortes anualmente. No diabetes Tipo 2 (DM 2), que incluí a grande maioria dos casos de DM (cerca de $90 \%$ dos pacientes diabéticos), é caracterizada por um quadro de resistência insulínica $(\mathrm{RI})$. O possível elo entre DM2 e inflamação é a RI. A reação de inflamação induzida pelos fatores de risco e a resposta imunológica associada são eventos que podem conduzir ao processo de progressão do DM. Portanto, os marcadores de inflamação podem ser também alvos potenciais de terapia na prevenção ou no tratamento dessa patologia e de suas complicações. Já o exercício melhora a sensibilidade à insulina, diminui a hiperinsulinemia, aumenta a captação muscular de glicose, melhora o perfil lipídico e a hipertensão arterial, além da sensação de bem-estar físico e psíquico decorrente; também pode contribuir para a perda de peso. Relatos da literatura demonstraram, em indivíduos seguidos por vários anos, que a prática diária de exercícios físicos diminuiu a incidência de DM em aproximadamente 50\%. Objetivo: O objetivo deste projeto foi levantar, prospectivamente, indivíduos diabéticos e indivíduos saudáveis, com níveis glicêmicos e perfil de atividade física conhecidos e correlacionar dados clinico-epidemiologicos em estudo caso-controle comparando ambos os grupos diabéticos com o controle. Materiais e Métodos: Os indivíduos deste estudo foram divididos em quatro grupos: G1 (com DM2, sem treinamento físico) e G2 (com DM2, com treinamento físico determinado e conhecido), G3 (saudáveis, com treinamento físico determinado e conhecido) e G4 (saudáveis, sem treinamento físico). Os participantes foram submetidos a questionários clínicoepidemiológico, de atividade física (IPAQ) e foram aplicados testes glicêmicos. Resultados: Os dados coletados, na cidade de Jundiai, revelaram um N=37 em G1; 36\% deles apresentavam IMC normal, 25\% sobrepeso, $17 \%$ obesidade grau I, $14 \%$ obesidade grau II e $8 \%$ obesidade grau III. O histórico familiar de DM2 foi positivo para $86 \%$ dos indivíduos de G1. Entre os sintomas mais comuns apresentados por indivíduos com DM2 e sem atividade física associada, destacam-se o cansaço (64\%), a polidipsia (64\%) e poliúria (61\%), 21\% polifagia e $21 \%$ embaçamento visual. O grupo G2 incluiu um total de 47 indivíduos, dos quais o histórico familiar positivo para DM2 estava presente em $66 \%$, enquanto nenhum desses indivíduos apresentavam IMC normal, e 49\% apresentavam sobrepeso, 26\% obesidade grau I, 16\% obesidade grau II e $9 \%$ obesidade grau III. Neste mesmo grupo, $26 \%$ dos diabéticos se referiram cansaço, $17 \%$ polidipsia, $8 \%$ polifagia, $11 \%$ poliúria, $19 \%$ embaçamento visual e $4 \%$ dor em MMII e $15 \%$ não apresentava sintomatologia. Além disso, 80\% apresentavam patologias do sistema cardiovascular, o que sugere estudos futuros do nosso grupo para averiguar as bases genéticas desses indivíduos como um grupo de risco para a doença. Conclusão: É notável que o exercício físico pareceu contribuir para o melhor controle dessa patologia. Nota-se que a sintomatologia e queixas dos pacientes diabéticos que praticam exercício físico regular (G2) é bem menor (em porcentagem) quando comparado às dos pacientes diabéticos que não praticam exercício físico regular (G1), sobretudo nos pacientes com sobrepeso e obesos.

Palavras-Chave: diabetes mellitus tipo 2, glicemia, exercício físico, inflamação. 


\section{ANÁLISE DAS CONCENTRAÇÕES DA AMILASE SALIVAR E CORRELAÇÕES COM A SÍNDROME DE OVERTRAINING E LESÕES ESPORTIVAS, EM ATLETAS PROFISSIONAIS DE FUTEBOL}

Waldir Peres Neto', Breno Lemos do Carmo', Danilo Roberto Xavier de Oliveira Crege ${ }^{2}$.

1. Graduando do curso de Medicina; Faculdade de Medicina de Jundiaí.

2. Professor Adjunto da Disciplina de Fisiologia do Departamento de Biologia e Fisiologia da Faculdade de Medicina de Jundiaí (FMJ), Jundiaí/SP.

\section{Endereço para correspondência:}

Waldir Peres Neto - R. Waldomiro Lobo da Costa, no 45 - Vila Arens, Jundiaí-SP - CEP 13202-312. Tel.: (19) 98172-2010, e-mail: neto_peres_99@hotmail.com

\section{RESUMO:}

Introdução: A reação do organismo frente a uma condição estressora se dá através do eixo hipotálamo-hipófise-adrenal, que promove liberação de uma rede de hormônios que desencadeiam diferentes respostas fisiológicas. No meio esportivo, o estresse físico repetitivo de forma exaustiva pode promover aumento dos efeitos do sistema nervoso simpático e uma diminuição no desempenho esportivo do atleta, o que é denominado como síndrome de overtraining (SDO). Entre os marcadores estudados para avaliar a resposta ao estresse e SDO, temos a alfa-amilase salivar, que aumenta de concentração por conta da estimulação simpática e pode ser uma alternativa viável para analisar a SDO. Objetivos: O objetivo do presente estudo foi analisar o comportamento da enzima salivar alfaamilase de atletas de uma equipe de futebol, além de analisar se existem alterações psicofisiológicas dos atletas, por meio do questionário de overtraining, bem como correlacionar com eventuais lesões não traumáticas, ocorridas durante um período de competição. Metodologia: As coletas de salivas e aplicação dos questionários para análise do overtraing foram realizadas em três ocasiões, totalizando 34 atletas, durante o final da temporada 2019 e preparação da equipe para Copa São Paulo de Futebol Junior em janeiro de 2020. Além disso, foram mapeadas as lesões ocorridas nos atletas neste período. Resultados: Nossos resultados mostraram que houve maior percepção de sobrecarga de treinamento no mês de novembro $(18,65+2,10)$, o que não condiz com a maior incidência de lesões, que ocorreu no final de dezembro $(15,86+1,75)$ e janeiro $(13,31+1,23)$. Foram encontradas diferenças significativas, quando comparado os valores dos meses de novembro e janeiro, sendo que neste último mês a percepção da carga de treinamento pelos atletas era menor. Por conta de o clube não manter 0 acordo inicial e, em virtude da pandemia de coronavírus, não foi realizada a análise das amostras de saliva para dosagem da amilase salivar. Conclusões: Sugere-se que durante o período preparatório para as principais competições se tem um maior índice de estresse e SDO, devendo então atentar-se para uma possível sobrecarga de treinamento. Um outro ponto é que as lesões verificadas aconteceram após o período em que os atletas relataram maior percepção de sobrecarga de treinamento, mas próximo dos dias em que iniciaria a principal competição disputada pelos atletas, o que mostra que apesar da percepção reduzida do treinamento excessivo, pode haver uma carga maior de treino do que o tolerado.

Palavras-Chave: Overtraining, lesões esportivas, futebol. 


\title{
ANÁLISE DE DIÁRIOS ALIMENTARES DE ALUNOS DA REDE PÚBLICA DE JUNDIAÍ ANTES E APÓS PALESTRA EDUCATIVA SOBRE NUTRIÇÃO E SAÚDE HUMANA
}

\author{
Carolina Pires Cordeiro', Francisco Homero D`Abronzo².
}

1. Graduanda da Faculdade de Medicina de Jundiaí.

2. Professor Adjunto da Disciplina de Endocrinologia do Departamento de Clínica Médica, Faculdade de Medicina de Jundiaí (FMJ), Jundiaí/SP.

Carolina Pires Cordeiro - R. Francisco Telles, no 84, apto 71 - Vila Arens, Jundiaí-SP - CEP 13202550. Tel.: (11) 975731261, e-mail: carolinapcordeiro@gmail.com; fhdabronzo@gmail.com.

\section{RESUMO:}

Introdução A obesidade, uma condição de excesso de gordura no organismo, relacionada ao desenvolvimento de doenças crônicas como hipertensão, hipercolesterolemia, diabetes mellitus, vem sofrendo aumento de prevalência na faixa etária dos 5 aos 9 anos no Brasil. Entre os fatores de risco que predispõe a obesidade infantil tem-se a dieta pouco saudável, com ingestão de alimentos de alto valor calórico, ultraprocessados, ricos em gorduras e carboidratos refinados. Esse novo padrão de consumo alimentar revela uma substituição de agentes protetores cardiovasculares, como fibras e polifenóis, importantes na redução de tecido adiposo encontrado em alimentos "in natura", por produtos refinados com alta densidade energética. Uma forma de melhorar a qualidade do consumo e reduzir esses danos é a educação sobre alimentação saudável na infância. Ao considerar que é nesse período que ocorre a formação do hábito alimentar, a informação e entendimento dos fatores nele envolvidos, torna possível a mudança no padrão de consumo. No entanto, há uma carência de intervenções educacionais que motivem o aprendizado sobre hábitos saudáveis. Objetivo: Objetivou-se com esse trabalho qualificar a frequência alimentar infantil com o fim de comparação entre escolhas dos alimentos antes e após apresentação de palestras sobre nutrição e saúde humana Materiais e Métodos: Avaliouse o consumo alimentar dos alunos de terceiros e quartos anos, das escolas municipais de educação básica do município de Jundiaí (EMEB) antes e após intervenção de educação nutricional. A análise foi feita por meio de diários alimentares, tabelas com lacunas a serem assinaladas referentes ao alimento e o período do dia que fora ingerido. Os alunos da faculdade de medicina de Jundiaí do quarto ano, capacitados previamente pela disciplina de endocrinologia realizaram três visitas as EMEBs. Sendo a primeira com finalidade de orientação quanto ao preenchimento adequado dos diários e outras duas de intervenção por meio de palestras sobre a nutrição e saúde humana. Em todas as visitas cada criança recebeu dois diários a serem preenchidos, um referente a um dia de semana e outro a um dia do final de semana. Resultados: Nos resultados foram observados uma frequência elevada no relato de consumo de alimentos de alto valor energético, como gorduras e carboidratos refinados, atualmente designadas de alimentos ultraprocessados e, redução do consumo dos alimentos "in natura". O padrão nutricional mostrou melhora com diminuição de alimentos diabetogênicos e aumento de não diabetogêncos em resposta as palestras. Conclusão: Os alimentos consumidos com maior frequência pelas crianças têm sido sugeridos como causadores de diabetes tipo 2, obesidade e hipertensão arterial, aumentando o risco de obesidade infantil. Concluímos então que devemos focar daqui para frente especificamente sobre os itens aqui percebidos como inadequados a uma dieta saudável, além da orientação geral. Uma padronização do teor da palestra "nutrição e saúde humana" com ênfase na redução do consumo de ultraprocessadas, associados a obesidade e diabetes tipo2, e aumento o consumo de frutas, verduras, legumes e ovos, alimentos in natura em que o consumo se mostrou reduzido. Demandas estas percebidas com os dados e conclusão do presente trabalho.

Palavras-Chave: Obesidade infantil, diário alimentar, educação nutricional, alimentação infantil, prevenção obesidade infantil. 


\section{ANÁLISE DO REPARO ÓSSEO ENXERTADO COM SELANTE DE FIBRINA DERIVADO DO VENENO DE CASCAVEL}

Tiago Szwarc Porto ${ }^{1}$, Ivan Moreira Mezzacapa², Marcelo Rodrigues da Cunha ${ }^{3}$.

1. Graduando do curso de Medicina; Faculdade de Medicina de Jundiaí

2. Aluno da Pós-Graduação (Mestrado); Faculdade de Medicina de Jundiaí (FMJ), Jundiaí/SP.

3. Professor Orientador da Disciplina de Anatomia do Departamento de Morfologia e Patologia Básica, Faculdade de Medicina de Jundiaí (FMJ), Jundiaí/SP.

\section{Endereço para correspondência:}

Tiago Szwarc Porto - R. Moises Abaid, oo 181 - Jardim São Bento, Jundiaí-SP - CEP 13202-500. Tel.: (11) 99271-7469, e-mail: tiagosporto1@hotmail.com

\section{RESUMO:}

Diversas situações podem causar lesões ósseas nas quais a estrutura perde a capacidade de se regenerar espontaneamente e desta maneira há a necessidade do uso de enxerto autólogo. Entretanto, alguns biomateriais também se configuram como alternativa viável ao processo de estímulo do reparo ósseo, principalmente aqueles que funcionam como scaffold para a adesão, crescimento e proliferação celular. Dentre esses, destaca-se o selante de fibrina composta por veneno de cobras Crotalus durissus terrificas associada ao plasma de búfalas Bubalus bulais devidos as suas propriedades hemostáticas e cicatrizantes. Assim sendo, o objetivo desta pesquisa foi fazer uma revisão bibliográfica do uso desse específico e inovador selante de fibrina desenvolvido no CEVAP (UNESP, Botucatu/SP) em terapias de reconstrução óssea. Nos resultados, notou-se pesquisas recentes usando esse produto em pesquisas experimentais de reconstrução óssea e com dados que suportam o crescimento ósseo mediante ao enxerto deste selante. Desta maneira, conclui-se que esse material se torna uma alternativa promissora na medicina regenerativo do tecido ósseo.

Palavras-Chave: biomateriais, tecido ósseo, regeneração óssea. 


\section{AVALIAÇÃO CLÍNICA E ESTRATIFICAÇÃO DE RISCO NO CARCINOMA BEM DIFERENCIADO DA TIREOIDE: ANÁLISE DE DUAS COORTES LONGITUDINAIS E RETROSPECTIVAS 1961 a 1992 e 1993 a 2018}

Pedro Ferrarini de Oliveira Pimentel ${ }^{1}$, Renata Esteves Alves Jordão ${ }^{1}$, Melina Tavares Di Trani ${ }^{1}$, Júlia Mateus De Bei ${ }^{1}$, Aline Paterno Miazaki², Fernando Antonio Maria Claret Arcadipane ${ }^{3}$

1. Graduando do curso de Medicina; Faculdade de Medicina de Jundiaí.

2. Professora Colaboradora da Disciplina de Cabeça e Pescoço do Departamento de Cirurgia de Cabeça e Pescoço, Faculdade de Medicina de Jundiaí (FMJ), Jundiaí/SP.

3. Professor Adjunto da Disciplina de Cabeça e Pescoço do Departamento de Cirurgia de Cabeça e Pescoço da Faculdade de Medicina de Jundiaí (FMJ), Jundiaí/SP.

\section{Endereço para correspondência:}

Pedro Ferrarini de Oliveira Pimentel R. Zuferey, no183 (apto 304, bloco3) - Vila Arens Jundiaí-SP CEP 13202-420. Tel.: (11) 96196-5252, e-mail: pimentelpedro010@gmail.com

\section{RESUMO:}

Introdução: O carcinoma da tireoide é o mais comum dos tumores endócrinos e divide-se em tumores bem diferenciados e não diferenciados. Entre os bemdiferenciados, o carcinoma papilífero e 0 carcinoma folicular representam mais que $90 \%$ dos casos. O tumor da tireoide consiste no quinto tumor mais prevalente em mulheres no Brasil e sua incidência aumenta globalmente nos últimos anos. Os sistemas de estratificação de risco são indispensáveis para identificar os níveis de sua agressividade, destacam-se três sistemas de classificação: $\mathrm{TNM}^{*}$, ATA ${ }^{* \star}$ e DRS ${ }^{\star * *}$. Objetivo: Avaliar estratificação de risco do carcinoma bem diferenciado da glândula tireoide nas coortes analisadas de 1961 a 1992 e de 1993 a 2018. Materiais e Métodos: Estudo de coorte longitudinal retrospectivo, em dois períodos de análise comparativa, de prontuários de doentes com o diagnóstico de carcinoma bem diferenciado da glândula tireoide. Após aplicados os critérios de inclusão e de exclusão, foram estudadas as seguintes variáveis: dados demográficos, história clínica, exame locorregional, dados cirúrgicos, exame anatomopatológico da peça operatória, exames complementares, tratamentos complementares e "status" do seguimento. Finalmente, os dados levantados serão submetidos à análise estatística. Resultados: A descrição será sempre em primeiro lugar todas as características da coorte $1 \mathrm{com} 202$ pacientes seguida da coorte $2 \mathrm{com} 76$ pacientes. A maioria dos pacientes eram mulheres. Nos dados clínicos observamos que a queixa principal para procura de atendimento foi presença de nódulo em região cervical. $O$ tratamento cirúrgico instituído para todos os pacientes foi a tireoidectomia total. Entre os achados anatomopatológicos o carcinoma papilífero estava presente em $72,8 \%$ e $77,6 \%$ de todos os casos, o grau de diferenciação histológica foi predominantemente o bem diferenciado e o tumor primário na glândula tireoide foi mais incidente no lobo direito. Status: Pacientes vivos sem evidências de doença: 71,8\% e 96,1\%; Pacientes com recidivas locorregionais e/ou metástases a distância: 11,4\% e 3,9\%; Doentes que faleceram pelo CBDT: $8,9 \%$ e $0,0 \%$; Doentes que faleceram por causa não relacionada ao CBDT: 14,9\% e 0,0\%; Doentes que não puderam ser contatados no período do último levantamento, considerados como perda de seguimento: $4,5 \%$ e $0,0 \%$. Conclusão: Com os dados obtidos e analisados apenas descritivamente observamos que a resposta ao tratamento inicial foi superior na coorte 2, mas com estratificação de risco obtida com grande número de dados ausentes nos prontuários. Não observamos diferenças numéricas nos dados demográficos, clínicos e cirúrgicos entres as duas coortes.

Palavras-Chave: Carcinoma bem diferenciado, glândula tireoide, estratificação de risco, tireoidectomia total. 


\section{AVALIAÇÃO DA ADESÃO AO TRATAMENTO DE HIPERTENSÃO ARTERIAL SISTÊMICA}

Bruno Fromm Tonus, Raphael Sakahara Saito', Maria Helena Sousa², Flávia Lilalva de Holanda

1. Graduando do curso de Medicina; Faculdade de Medicina de Jundiaí.

2. Professora Adjunta da Disciplina de Pesquisa em Saúde do Departamento de Saúde Coletiva da Faculdade de Medicina de Jundiaí (FMJ), Jundiaí/SP.

3. Professora Adjunta da Disciplina de Pesquisa em Saúde do Departamento de Saúde Coletiva da Faculdade de Medicina de Jundiaí (FMJ), Jundiaí/SP.

\section{Endereço para correspondência:}

Autor: Bruno Fromm Tonus - Rua Loefgreen, no 1543 - Vila Clementino São Paulo, São Paulo-SP CEP 04040-032. Tel.: (11) 59043812, e-mail: brunofromm99@gmail.com.

\section{RESUMO:}

Introdução: A hipertensão arterial sistêmica (HAS) é uma doença que está cada vez mais em destaque no âmbito da saúde pública, devido à sua prevalência e complicações. Com isso, a adesão ao tratamento proposto é de fundamental importância. Objetivos: Avaliar a prevalência da adesão ao tratamento da HAS entre pessoas adultas em acompanhamento no ambulatório de especialidades da Faculdade de Medicina de Jundiaí. Como objetivos específicos, tem-se: estimar a prevalência da adesão ao tratamento; identificar as características sociodemográficas da amostra e verificar os fatores associados à adesão à terapêutica anti-hipertensiva. Método: Estudo descritivo transversal, com abordagem quantitativa. Foram incluídas pessoas hipertensas, em acompanhamento ambulatorial, com pelo menos 18 anos de idade. Construiu-se questionário com dados semiestruturados e duas escalas validadas. Usou-se para verificar adesão medicamentosa, a Medida de Adesão ao Tratamento (MAT). Já para a adesão ao tratamento da HAS e o conhecimento sobre ela, aplicou-se o Teste de Batalla. Também, buscou-se compreender como os fatores relacionados à alimentação, aos hábitos comportamentais e aos medicamentos interferem e culminam na adesão ao tratamento da hipertensão. A coleta foi realizada pelos estudantes de medicina, no ambulatório da faculdade. Realizou-se análise estatística unidimensional e bidimensional com o programa SPSS. Resultados: A amostra foi composta por 152 pessoas em sua maioria mulheres, com menos de 70 anos, casadas, brancas e com ensino fundamental 2 completo. Dos participantes, 134 (89,9\%) aderem ao tratamento medicamentoso segundo a MAT, $58(38,2 \%)$ aderem ao tratamento e tem conhecimento sobre HAS de acordo com Batalla e $16(10,5 \%)$ aderem ao tratamento não medicamentoso. Houve associação estatisticamente significativa entre a MAT e o número de moradores na casa e a quantidade de anti-hipertensivos que a pessoa toma. Em relação ao Batalla, a significância foi com estado civil e histórico de infarto agudo do miocárdio. Conclusões: Identificou-se que a prevalência da adesão foi menor pelo Teste do Batalla e maior pelo MAT, mostrando que há deficiência no conhecimento dos participantes sobre a doença. Estratégias devem ser tecidas para estimular e aumentar a adesão ao tratamento dos hipertensos, principalmente em relação à informação e ao conhecimento. A Educação em saúde é valiosa e essencial para diminuir os fatores intervenientes, as morbidades e a mortalidade.

Descritores: Pressão Arterial; Hipertensão; Adesão à Medicação; Cooperação e Adesão ao Tratamento; Pacientes Ambulatoriais. 


\section{AVALIAÇÃO DA PERCEPÇÃO DE HIGIENE ORAL NO DESENVOLVIMENTO DE CARCINOMA ESPINOCELULAR DE CAVIDADE ORAL}

Thamires Clair Rodrigues Pereira da Silva ${ }^{1}$, Lívia Ernandes Simas ${ }^{1}$, Marcela Valente Ventura ${ }^{1}$, Camila Guimarães Aguiar Akamine², Fernando Antônio Maria Claret Alcadipani ${ }^{3}$, Clóvis Antônio Lopes Pinto 4

1. Graduando do curso de Medicina; Faculdade de Medicina de Jundiaí

2. Professora Colaboradora da Disciplina de Cirurgia de Cabeça e Pescoço do Departamento de Cirurgia da Faculdade de Medicina de Jundiaí (FMJ), Jundiaí/SP.

3. Professor Adjunto da Disciplina de Cirurgia de Cabeça e Pescoço do Departamento de Cirurgia, Faculdade de Medicina de Jundiaí (FMJ), Jundiaí/SP.

4. Professor Adjunto da Disciplina de Patologia Geral e Especial do Departamento de Morfologia e Patologia, Faculdade de Medicina de Jundiaí (FMJ), Jundiaí/SP.

\section{Endereço para correspondência:}

Thamires Clair Rodrigues Pereira da Silva - R. Zuferey, no 155 - Vila Arens, Jundiaí-SP - CEP 13202420. Tel.: (11) 97515-9693, e-mail: thamires.crps@gmail.com.

\section{RESUMO:}

Introdução: $O$ carcinoma espinocelular (CEC) de cabeça e pescoço é o sexto tipo de câncer mais comum no mundo, com incidência e mortalidade que crescem a cada ano. O CEC de cavidade oral acomete principalmente homens acima dos 40 anos e é mais comum em países em desenvolvimento. Anualmente, diagnostica-se mais de 300.000 casos e tem-se cerca de 145.000 óbitos por câncer de cavidade oral. Apresenta-se como um problema de saúde pública global, é um dos dez canceres mais incidentes e, embora haja processo na terapia, a sobrevida não melhorou significativamente nos últimos anos. Objetivo: O presente trabalho tem como objetivo geral comparar hábitos de higiene oral em um grupo que desenvolveu CEC de cavidade oral com um grupo que não possui tal doença. Materiais e Métodos: Trata-se de um estudo primário, observacional, analítico, transversal, retrospectivo, do tipo caso-controle, realizado no ambulatório de especialidades da Faculdade de Medicina de Jundiaí. Tendo como amostra total 40 participantes, sendo 20 pacientes do grupo caso (pacientes com CEC de cavidade oral) e 20 do grupo controle (pacientes sem CEC de cavidade oral). Foram realizadas análises estatísticas para relacionar as variáveis e foram calculados odds ratio (OR) e o intervalo de confiança de 95\% (IC95\%). Resultados: Pacientes do sexo masculino (OR=5,57; IC95\% 1,19-27,63), aqueles que fumam ou fumaram (OR=9,33; IC95\% 1,82 - 52,68), os que bebem ou bebiam (OR=8,5; IC $95 \%$ $1,56-56,85)$ e pacientes que apresentaram lesões orais ( $O R=2$; IC95\% 0,43 - 9,82) têm maiores chances de desenvolver CEC de cavidade oral. Conclusão: Encontrou-se poucas diferenças em relação à higiene oral entre os grupos. Quanto à atividade sexual e fatores sociodemográficos, as diferenças são consideradas irrelevantes. Propomos medidas preventivas para a população mais suscetível.

Palavras-Chave: Higiene Bucal, Neoplasias Bucais, Etiologia. 


\title{
AVALIAÇÃO DA PERCEPÇÃO E CONHECIMENTO DE ONCOLOGISTAS BRASILEIROS SOBRE EPIGENÉTICA
}

\author{
Emanuella Dutra Gonçalves ${ }^{1}$, Beatriz Cantieri Almeida ${ }^{1}$, Marília Jesus Batista de Brito Mota², \\ Aline Cristiane Planello ${ }^{3}$.
}

1. Graduanda do curso de Medicina; Faculdade de Medicina de Jundiaí

2. Professora Adjunta da Disciplina de Prática em Saúde Coletiva do Departamento de Saúde Coletiva da Faculdade de Medicina de Jundiaí (FMJ), Jundiaí/SP.

3. Professora Adjunta da Disciplina de Genética do Departamento de Morfologia e Patologia Básica, Faculdade de Medicina de Jundiaí (FMJ), Jundiaí/SP.

\section{Endereço para correspondência:}

Emanuella Dutra Gonçalves - R. Visconde de Taunay, № 206, apto 005 - Vila Arens II, Jundiaí-SP CEP 13202-540. Tel.: (11) 94210-1515, e-mail: manugonc@hotmail.com.

\section{RESUMO:}

Introdução: A epigenética pode ser definida como alterações na expressão gênica que ocorrem independentemente de alterações na sequência do DNA. Mudanças no padrão epigenético podem ter efeitos danosos capazes de resultar em processos patológicos, como o desenvolvimento e a progressão do câncer. Além disso, os últimos anos tem testemunhado um investimento sem precedentes na elaboração, caracterização e tradução de terapias epigenéticas específicas. Portanto, por ser uma área relativamente nova e complexa, considera-se de extrema importância a averiguação da percepção e conhecimento dos médicos oncologistas sobre epigenética. Objetivo: Realizar a validação de construto e confiabilidade de instrumento desenvolvido e já validado quanto a face e conteúdo em projeto anterior e avaliar a percepção e conhecimento de oncologistas brasileiros sobre a epigenética. Materiais e Métodos: Estudo metodológico utilizando questionário autoaplicável de 27 itens em escala tipo likert de 5 pontos. A amostra foi composta por oncologistas brasileiros. Resultados: Foram considerados 56 participantes. A análise de Componentes Principais revelou oito fatores: "Conhecimentos", "Perspectivas futuras", "Percepções na medicina", "Domínio", "Atualizações", "Relevância", "Ensino" e "Perspectivas do ensino". O alfa de Cronbach de todos os itens foi de 0,581. A maioria dos participantes mostrou conhecimento do papel da epigenética no desenvolvimento do câncer e dos mecanismos epigenéticos envolvidos. Porém, 46,4\% relataram não possuir domínio desse conhecimento e $54,5 \%$ não se sentem seguros para prática clínica. Ainda, $60,8 \%$ não tiveram o tema durante a residência e 53,5\% não o têm visto ser abordado em congressos médicos. Apesar disso, todos os participantes concordaram que a epigenética deveria ser considerada com maior destaque dentro do aprendizado médico. Na análise bivariada, os participantes do gênero feminino $(p=0,047)$ e os que atuam em ambas redes pública e privada $(p=0,014)$ foram mais prováveis de expressarem percepções positivas em relação às "Percepções da Epigenética na Medicina"; o tempo de graduação $<20$ anos se associou a uma percepção mais positiva em relação ao fator "Ensino", enquanto que os participantes com mestrado ou doutorado demonstraram percepção e conhecimento superiores em relação aos fatores "Conhecimentos" $(p=0,022)$, "Perspectivas futuras" $(p=0,019)$ e "Domínio" $(p=$ 0,021). Conclusão: O questionário evidenciou ser confiável e consistente. Os dados indicam que, embora atualmente a aplicabilidade prática da epigenética entre os oncologistas brasileiros seja baixa, o interesse no aprendizado clínico é alto, o que provavelmente permitirá com que medidas futuras sejam tomadas a fim de proporcionar o progresso diagnóstico e terapêutico na oncologia.

Palavras-Chave: Epigenética, câncer, oncologia. 


\section{AVALIAÇÃO DA PERCEPÇÃO E CONHECIMENTO DE PSIQUIATRAS SOBRE FARMACOGENÉTICA}

Beatriz Cantieri Almeida ${ }^{1}$, Emanuella Dutra Gonçalves ${ }^{1}$, Maria José Martins Duarte Osis ${ }^{2}$, Aline Cristiane Planello ${ }^{3}$.

1. Graduando do curso de Medicina; Faculdade de Medicina de Jundiaí

2. Professora Adjunta da Disciplina de Pesquisa em Saúde do Departamento de Saúde Coletiva da Faculdade de Medicina de Jundiaí (FMJ), Jundiaí/SP.

3. Professora Adjunta da Disciplina de Genética do Departamento de Morfologia e Patologia Básica, Faculdade de Medicina de Jundiaí (FMJ), Jundiaí/SP.

\section{Endereço para correspondência:}

Beatriz Cantieri Almeida - R. Visconde de Taunay, ํㅡ 206 - Vila Arens, Jundiaí-SP - CEP 13202-540. Tel.: (35) 998213722, e-mail: biacantieri@icloud.com

\section{RESUMO:}

Introdução: A farmacogenética é uma área do conhecimento médico-científico que se destaca por sua potencialidade em aprimorar terapias medicamentosas quanto a escolha do fármaco e da dose adequadas de forma individual. Numerosas investigações sobre interações gene-fármaco na psiquiatria se somam à grande variabilidade genética no Brasil e à acessibilidade progressiva aos testes genéticos, tornando necessária a avaliação da percepção e do conhecimento de psiquiatras, cuja especialidade médica mais tem se beneficiado dos avanços na farmacogenética. Objetivo: Realizar a validação de construto e confiabilidade de instrumento desenvolvido e já validado quanto a face e conteúdo em projeto anterior, e avaliar a percepção e conhecimento de psiquiatras brasileiros sobre farmacogenética. Materiais e Métodos: trata-se de estudo metodológico utilizando questionário autoaplicável, com 26 itens em escala tipo Likert de 5 pontos, em amostra composta por psiquiatras brasileiros. A análise de consistência interna do instrumento utilizou teste Alfa de Cronbach. A análise de Componentes Principais foi usada para redução das dimensões e o Teste $U$ de Mann-Whitney para análise bivariada. Resultados: Um total de 71 psiquiatras respondeu ao questionário. A análise fatorial revelou 8 fatores. $O$ alfa de Cronbach mostrou moderada a forte consistência interna do questionário $(0,7)$. O tempo médio de graduação dos participantes foi de 18 anos. $85,9 \%$ consideram possuir algum conhecimento acerca do tema, embora apenas $14,1 \%$ considerarem que a maioria dos psiquiatras possui tal conhecimento. Na aplicação prática, 49,3\% e 60\% consideraram necessário consultar colegas para discutir os processos de solicitação e interpretação de testes farmacogenéticos, respectivamente. A maioria (78,9\%) dos participantes não teve o tema abordado em seu programa de residência médica e acreditava que a farmacogenética deveria ter maior destaque na formação médica $(91,6 \%)$. Na análise bivariada, o grupo com idade $<40$ anos apresentou uma percepção menos positiva no fator "Percepções da Farmacogenética na Medicina" ( $p=0,030)$. O gênero feminino foi mais provável de expressar percepções positivas $(p=0,031)$ em relação às "Percepções sobre ensino da Farmacogenética". Os médicos que atuavam exclusivamente na rede privada mostraram maior "Autoconfiança na utilização de testes" ( $p=0,031)$. Conclusão: O questionário evidenciou ser confiável e consistente. Apesar dos profissionais terem demonstrado familiaridade com o tema e reconhecido sua importância, a Farmacogenética ainda está distante de ser uma ferramenta comumente utilizada no cotidiano dos psiquiatras brasileiros, revelando a importância do desenvolvimento de recursos educacionais sobre farmacogenética clínica para psiquiatras, de forma a ampliar a sua implementação.

Palavras-Chave: Farmacogenética; genética; polimorfismo. 


\section{AVALIAÇÃO DA PREVALÊNCIA DE SÍNDROME DO ANTICORPO ANTIFOSFOLÍPIDE NOS PACIENTES DAS DISCIPLINAS DE HEMATOLOGIA E REUMATOLOGIA DO AMBULATÓRIO DE ESPECIALIDADES DA FACULDADE DE MEDICINA DE JUNDIAÍ E DO AMBULATÓRIO DE PRÉ-NATAL - SAÚDE DA MULHER/PMJ}

Leonardo Wiltemburg Alves Todari ${ }^{1}$, Henrique Vivacqua Leal Teixeira de Siqueira ${ }^{1}$, Marília Soares e Silva Arcadipane², José Celso Giordan Cavalcanti Sarinho³, Ricardo Porto Tedesco ${ }^{4}$, Hélio Alvimar Lotério5.

1. Graduando do curso de Medicina; Faculdade de Medicina de Jundiaí.

2. Professora Adjunta da Disciplina de Propedêutica do Departamento de Clínica Médica da Faculdade de Medicina de Jundiaí (FMJ), Jundiaí/SP.

3. Professor Adjunto da Disciplina de Reumatologia do Departamento de Clínica Médica da Faculdade de Medicina de Jundiaí (FMJ), Jundiaí/SP.

4. Professor Adjunto da Disciplina de Ginecologia e Obstetrícia do Departamento de Tocoginecologia da Faculdade de Medicina de Jundiaí (FMJ), Jundiaí/SP.

5. Professor Adjunto da Disciplina de Hematologia do Departamento de Clínica Médica da Faculdade de Medicina de Jundiaí (FMJ), Jundiaí/SP.

\section{Endereço para correspondência:}

Leonardo Wiltemburg Alves Todari - R. Francisco Telles, no 84, apto 122 - Vila Arens, Jundiaí-SP CEP 13 202-550. Tel.: (19) 99666-0090, e-mail: leotodari@gmail.com.

\section{RESUMO:}

Introdução: A Síndrome Antifosfolípide (SAF) é uma doença autoimune que está entre as principais causas de trombofilia adquirida no mundo, na qual anticorpos antifosfolípides (AAF), como o anticorpo anticardiolipina, anticoagulante lúpico e anti- $\beta 2$-glicoproteína I, desempenham importante papel na gênese das manifestações clínicas encontradas na doença. A trombose é a manifestação mais comum, podendo acometer qualquer órgão, sendo venosa ou arterial, acarretando, ainda, em intercorrências na gestação. O diagnóstico é essencialmente clínico e laboratorial (presença de anticorpos no sangue) e o tratamento se dá a partir da anticoagulação (principalmente por meio da Varfarina). Objetivo: Avaliar a prevalência dos pacientes com SAF no Ambulatório de Especialidades da Faculdade de Medicina de Jundiaí (Hematologia e Reumatologia) e no Ambulatório de Pré-Natal - Saúde da Mulher/PMJ no período de Agosto de 2019 até Junho de 2020, determinando as principais manifestações clínicas e complicações da doença. Materiais e Métodos: Este estudo foi submetido ao Comitê de Ética pela Plataforma Brasil, com $n^{\circ}$ de protocolo 076914/2019. Trata-se de um estudo clínico, observacional, transversal, descritivo, não controlado de prevalência, pela avaliação dos prontuários dos pacientes com SAF em seguimento no AE-FMJ (Hematologia e Reumatologia) e no Ambulatório de Pré-Natal - Saúde da Mulher/PMJ através de um questionário previamente elaborado. Resultados: Foram analisados 29 prontuários do AE-FMJ e foram analisados de acordo com sexo, idade ao diagnóstico, eventos trombóticos e exames realizados ao diagnóstico, tratamento realizado, efeitos colaterais das medicações, retrombose após o tratamento, gestação após diagnóstico e presença de doença autoimune na família. No Ambulatório de Pré-Natal - Saúde da Mulher/PMJ foram avaliados 119 prontuários de pacientes, das quais somente uma se encontrava em investigação para SAF e nenhuma possuía o diagnóstico firmado. Conclusão: Traçar um desenho estatístico dos casos nos ambulatórios, bem como os tipos de tratamento, e fazer um paralelo com os estudos de revisão é de grande importância, e foi um dos pilares dessa pesquisa. No Ambulatório de Pré-Natal - Saúde da Mulher/PMJ foi possível identificar o porquê de uma baixa incidência de casos, a partir de dados da literatura atual.

Palavras-Chave: anticorpo antifosfolípide; trombose; aborto. 


\title{
AVALIAÇÃO DA PREVALÊNCIA DE TABAGISMO EM ADOLESCENTES RESIDENTES NO MUNICÍPIO DE JUNDIAÍ
}

\author{
Luisa Mello Cotrim-Ferreira ${ }^{1}$, Catarina Ceolin Silva ${ }^{1}$, Eduardo Ponte ${ }^{2}$.
}

1. Graduanda do curso de Medicina; Faculdade de Medicina de Jundiaí

2. Professor adjunto da Disciplina de Propedêutica do Departamento de Clínica Médica da Faculdade de Medicina de Jundiaí (FMJ), Jundiaí/SP.

\section{Endereço para correspondência:}

Luisa Mello Cotrim-Ferreira - R. Vigário João José Rodrigues, № 31 - Centro, Jundiaí-SP - CEP 13201001. Tel.: (11) 97456-6555, e-mail: luisacotrimferreira@gmail.com

\section{RESUMO:}

Introdução A adolescência é um período da vida marcado por diversas mudanças e nele ocorre um aumento da prática de comportamentos arriscados. O tabagismo mata mais da metade de seus usuários e $90 \%$ dos tabagistas experimentaram seu primeiro cigarro antes dos 18 anos. Isso mostra a importância das medidas de saúde pública para diminuir o número de novos fumantes. Objetivo: Avaliar a prevalência de tabagismo em adolescentes residentes do município de Jundiaí e identificar fatores associados. Materiais e Métodos: Trata-se de um estudo transversal. Foram avaliadas crianças entre 10 e 18 anos residentes no município de Jundiaí que aguardavam atendimento no pronto atendimento do Hospital Universitário. Foram aplicados questionário sociodemográfico desenvolvido pelos pesquisadores e questionário adaptado do Global Youth Tobacco Survey. Resultados Devido a imprevistos com a aprovação no CEP e relacionados à pandemia do SARS-CoV 2, a coleta de dados foi interrompida pouco depois de seu início. Com isso, a amostra do estudo ficou limitada a sete adolescentes, dos quais todos negaram tabagismo. A idade mediana foi de 13 (12-14) anos. Apenas 1 indivíduo foi do sexo masculino. A mediana do número de pessoas que moram na mesma casa foi de 4 (3-5) pessoas, e a renda familiar em reais referida foi de 2.000 (1.100 - 5.200) reais. As medianas de anos de estudo do pai e da mãe dos adolescentes analisados foi de 11 e 7 anos, respectivamente. Dos adolescentes entrevistados, 1 (14\%) alegou tratar alguma doença crônica, 1 (14\%) referiu chiado no peito nos últimos 12 meses, nenhum declarou internação hospitalar nos últimos 12 meses, 1 (14\%) referiu história de tabagismo atual em alguém que mora na mesma casa e $3(43 \%)$ referiu história atual e/ou prévia de tabagismo na família. A análise comparativa entre os grupos mostra que adolescentes com história familiar de tabagismo atual e/ou prévia tinham maior frequência de doença crônica e chiado no peito, possuíam menor renda familiar e os pais tinham menor escolaridade. As diferenças não foram estatisticamente significância devido ao tamanho da amostra. Conclusão: Não identificamos nesta pequena amostra adolescentes tabagistas. Adolescentes com relato familiar de tabagismo atual e/ou passado tem menor escolaridade dos pais, menor renda familiar, mais doenças crônicas e chiado na comparação com famílias sem histórico de tabagismo. É preciso ampliar a coleta desses dados para que permitir conclusões válidas.

Palavras-Chave: tabagismo, adolescência, epidemiologia. 


\section{AVALIAÇÃO DA RELAÇÃO DE INDICADORES SOCIOECONÔMICOS COM O ÍNDICE DE ESTRESSE PERCEBIDO E QUALIDADE DE VIDA EM ESTUDANTES PRÉ-VESTIBULARES}

Vinicius Silva Torrero ${ }^{1}$, Danilo Roberto Xavier De Oliveira Crege².

1. Graduando do curso de Medicina; Faculdade de Medicina de Jundiaí

2. Professor Adjunto da Disciplina de Fisiologia do Departamento de Biologia e Fisiologia da Faculdade de Medicina de Jundiaí (FMJ), Jundiaí/SP.

\section{Endereço para correspondência:}

Vinicius Silva Torrero - R. Francisco Morato, no 191 - Vila Vianelo, Jundiaí-SP - CEP 13207-250. Tel.: (11) 981302822, e-mail: vinicius.s.t1998@gmail.com.

\section{RESUMO:}

Introdução: A sociedade atual demanda sucesso, tanto no âmbito social como profissional, o que exige decisões difíceis e um currículo acadêmico extenso e impecável, e essas pressões atuam como fatores desencadeantes de estresse. Em conjunto com essas pressões, condições socioeconômicas desfavoráveis, como uso de transporte público, a preocupação com renda para manter as atividades acadêmicas, também são fatores estressores da vida estudantil. Os fatores estressores desencadeiam depressão e ansiedade nos estudantes pré-universitários, ou seja, estes alunos estão sujeitos a um quadro grave de estresse. Embora em uma linha de raciocínio lógico e no senso comum, a associação de condições socioeconômicas precárias em estudantes pré-vestibulares esteja causando uma elevação dos níveis de estresse, prejudicando a qualidade de vida, seja reconhecida, na literatura acadêmica não há estudos que embasem esta associação. Objetivo: O objetivo do trabalho foi avaliar se as condições socioeconômicas afetam o índice de estresse percebido, assim como a qualidade de vida de alunos em cursos pré-vestibulares. Materiais e Métodos: Foram selecionados 202 alunos, que responderam três questionários: Escala de Estresse Percebido; Escala de Qualidade de Vida - SF36 e uma adaptação do questionário socioeconômico do INEP. Os estudantes responderam um questionário em agosto e outro em dezembro de 2019. Resultados: $\mathrm{Na}$ análise estatística dos resultados dos questionários de estresse percebido verificou-se uma diminuição significativa do índice de estresse percebido, quando comparadas as avaliações para os alunos do cursinho popular. Além disso, observou-se que os alunos do cursinho popular apresentaram um índice de estresse percebido significativamente maior na avaliação inicial, comparado aos alunos dos cursinhos particulares. Com relação ao questionário de qualidade de vida - SF 36, não foram encontradas diferenças estatisticamente significativas na análise de ambos os tipos de cursinhos. O questionário adaptado do INEP mostrou que os estudantes de cursinho popular em sua maioria são de classes menos favorecidas, enquanto os dos particulares tem melhores condições financeiras, o que pode ter influenciado os resultados obtidos. Conclusão: Os resultados mostraram que a classe social pode ter uma relação com o índice de estresse percebido, já que na primeira coleta de dados os estudantes do cursinho popular tiveram uma média de estresse maior, que a dos estudantes de cursinhos particulares, entretanto, isso não afetou a qualidade de vida desses estudantes.

Palavras-Chave: Estresse, Qualidade de vida, Pré-vestibular. 


\section{AVALIAÇÃO DO EFEITO DO TRATAMENTO COMBINADO COM METFORMINA E SINVASTATINA SOBRE A RESPOSTA INFLAMATÓRIA DE MACRÓFAGOS ESTIMULADOS COM CRISTAIS DE COLESTEROL}

João Remesso Ferreira Reinaldi ${ }^{1}$, Alana Tamyris Gomes Martins ${ }^{1}$, Vinicius Silva Torrero', Ana Lúcia Bergamasco Galastri², Ronei Luciano Mamoni ${ }^{3}$

1. Graduando do curso de Medicina; Faculdade de Medicina de Jundiaí

2. Técnica de Laboratório da Disciplina de Microbiologia do Departamento de Morfologia e Patologia Básica da Faculdade de Medicina de Jundiaí (FMJ), Jundiaí/SP.

3. Professor Adjunto da Disciplina de Imunologia do Departamento de Morfologia e Patologia Básica, Faculdade de Medicina de Jundiaí (FMJ), Jundiaí/SP.

\section{Endereço para correspondência:}

João Remesso Ferreira Reinaldi - R. Zuferey, oo211 - Vila Arens, Jundiaí-SP - CEP 13202-420. Tel.: (11) 964980212, e-mail: joaorfreinaldi@gmail.com.

\section{RESUMO:}

Introdução: A aterosclerose é uma das principais causas de mortalidade e morbidade no mundo. Dentre os fatores de risco associados têm-se os altos níveis de colesterol circulante (LDL) e o diabetes tipo 2. A formação da placa aterosclerótica envolve a deposição de lipídios na íntima arterial e a consequente ativação de uma resposta inflamatória, na qual os macrófagos desempenham papel preponderante, após ativação principalmente por cristais de colesterol. Alguns estudos mostram que a ativação de macrófagos por cristais de colesterol envolve a participação de receptores intracelulares conhecidos como NLRP3, que levam à produção de citocinas como a IL-1beta e IL-18. A prevenção e o tratamento das doenças cardiovasculares com estatinas para a redução dos níveis circulantes de colesterol estão bem estabelecidos. O mesmo ocorre com o uso de metformina para a diminuição dos níveis circulantes de glicose e consequentemente no tratamento/prevenção de diabetes do tipo 2 . Diversos estudos têm demonstrado o potencial anti-inflamatório dessas drogas, embora seus efeitos na modulação da resposta imunológica e na ativação do inflamassoma NLRP3 permaneça controverso. Objetivo: Investigar o efeito do tratamento combinado com sinvastatina e metformina na resposta inflamatória e na ativação do inflamassoma NLRP3 em macrófagos estimulados com cristais de colesterol. Materiais e Métodos: Macrófagos derivados de células THP-1 foram mantidos sem tratamento ou tratados in vitro com diferentes concentrações de Metformina e/ou Sinvastatina e depois estimulados com cristais de colesterol ou LPS (controle positivo de estimulação) por 48 horas. Após esse período os sobrenadantes de cultura foram coletados e os níveis de IL-1beta e TNF-alfa foram determinados por ELISA. Resultados preliminares: Até o momento, foram realizadas as padronizações das condições de cultura e das reações imunoenzimáticas para dosagem de citocinas. Observamos que o estímulo com LPS induz a produção de IL-1beta, IL-6, TNF-alfa e IL-18 e que o estímulo com cristal de colesterol induz IL-1beta e IL-18. Conclusão: Ainda não foi possível finalizar os experimentos previstos no projeto original. As atividades presenciais dos alunos no laboratório tiveram de ser interrompidas (março de 2020) devido às medidas adotadas em decorrência da pandemia de COVID-19 (causada pelo SARS-CoV-2). Essas medidas proibiram o acesso dos alunos aos laboratórios da FMJ, e dessa forma impediram a continuidade do projeto. Esperamos que assim que essas medidas sejam relaxadas, retomemos as atividades para a finalização do projeto inicialmente proposto.

Palavras-Chave: Doenças cardiovasculares, NLRP3, Sinvastatina, Metformina, Cristal de Colesterol. 


\section{AVALIAÇÃO DO PAPEL DA HEPARANASE-1 (HPSE-1) PRODUZIDA POR CÉLULAS TUMORAIS PROSTÁTICAS NA DIFERENCIAÇÃO E POLARIZAÇÃO DOS MONÓCITOS HUMANOS (THP-1) EM MACRÓFAGOS}

Thais Noto Faria ${ }^{1}$, Ronei Luciano Mamoni², Nilva Cervigne Furlan³ ${ }^{3}$, Taize Machado Augusto ${ }^{4}$

1. Graduando do curso de Medicina; Faculdade de Medicina de Jundiaí.

2. Professor Adjunto - Disciplina de Imunologia do Departamento de Morfologia e Patologia Básica, Faculdade de Medicina de Jundiaí (FMJ), Jundiaí/SP.

3. Professora Adjunta - Disciplina de Hematologia do Departamento de Clínica Médica da Faculdade de Medicina de Jundiaí (FMJ), Jundiaí/SP.

4. Professora Adjunta - Disciplina de Hematologia do Departamento de Clínica Médica da Faculdade de Medicina de Jundiaí (FMJ), Jundiaí/SP.

\section{Endereço para correspondência:}

Thais Noto Faria - R. Francisco Telles no 84 - Vila Arens, Jundiaí-SP - CEP 13202-550. Tel.: (11) 97102-8387 e-mail: thais.noto@gmail.com.

\section{RESUMO:}

Introdução: Investigações sobre o câncer de próstata, em modelos experimentais in vitro, evidenciam diversas linhagens celulares derivadas de câncer de próstata humano como é o caso da linhagem PC3. Entre outras células do tecido conjuntivo atuando em cooperação com as células tumorais células, destacamos os macrófagos M1, promovendo respostas antitumorais, e M2, relacionado com a progressão do tumor. Densos infiltrados dos macrófagos associados a tumor são observados no câncer de próstata, tendo como componente significante o fenótipo M2. A molécula HPSE1 está relacionada a polarização desses leucócitos, tanto para o fenótipo pro-inflamatório quanto pro-tumorigênico. A HPSE1 é uma enzima que tem a capacidade de clivar as cadeias de heparan sulfato presentes em alguns proteoglicanos, assim liberando várias outras moléculas na matriz extracelular. Quando superexpressa no tumor, ela pode iniciar ou aumentar processos relacionados ao desenvolvimento tumoral, atuando nos processos de metástase, proliferação de células tumorais e neovascularização. Objetivo: Analisar a diferenciação fenotípica e polarização in vitro de monócitos humanos (THP-1) em macrófagos na presença de HPSE1 presente no meio condicionado da cultura de células PC3 e seu clone com inibição estável HPSE1 (PC3 shHPSE). Métodos: Este estudo verificará a produção de citocinas pró e anti-inflamatórias (IL-1 $\beta$ e TNF- $\alpha$ ) através do ensaio de ELISA e de atividade de peroxidase. Também será verificado por microscopia de luz o fenótipo dos macrófagos diferenciados, assim como a expressão de marcadores celulares das populações de macrófagos diferenciados (CD206 (PE-Cy7), anti-CD163 (PercP) e anti-HLADR (MHC II) (PE-Cy7)), a partir da linhagem THP-1 em M1 e/ou M2 pela presença de HPSE1 por citometria de fluxo. Resultados esperados: Devido a pandemia COVID-19, não foi possível ainda completar os experimentos. No entanto, estudos evidenciam uma forte correlação entre a expressão da HPSE-1 no microambiente tumoral e a presença de macrófagos tipo M2, principalmente durante o processo de progressão tumoral. Neste estudo esperamos encontrar esta correlação mais íntima, como a direta participação da HPSE1 nesta modulação fenotípica e fisiológica dos macrófagos associados ao tumor. Conclusões: Este estudo encontra-se em fase de padronização da diferenciação dos monócitos humanos THP-1 em macrófagos e da coleta de meio condicionado pelas células tumorais prostáticas. Não podemos exibir quaisquer resultados neste momento por se tratar de um estudo em fase inicial.

Palavras-chave: HPSE-1; câncer de próstata; macrófagos. 


\title{
AVALIAÇÃO DOS EFEITOS DA METFORMINA SOBRE A RESPOSTA INFLAMATÓRIA DE CÉLULAS MONONUCLEARES DO SANGUE PERIFÉRICO E NEUTRÓFILOS DE INDIVÍDUOS COM ARTRITE PSORIÁSICA
}

\author{
Lais Aparecida Branco Zanchetta ${ }^{1}$, Giovanni de Paula Jorge Toso ${ }^{1}$, Théo Dechichi',
} Ana Lúcia Bergamasco Galastri², Waldenise Cossermelli ${ }^{3}$, Ronei Luciano Mamoni ${ }^{4}$.

1. Graduando do curso de Medicina; Faculdade de Medicina de Jundiaí

2. Técnica de Laboratório (Colaborador) da Disciplina de Microbiologia do Departamento de Morfologia e Patologia Básica da Faculdade de Medicina de Jundiaí (FMJ), Jundiaí/SP.

3. Professora Adjunta da Disciplina de Reumatologia do Departamento de Clínica Médica, Faculdade de Medicina de Jundiaí (FMJ), Jundiaí/SP.

4. Professor Adjunto da Disciplina de Imunologia e Microbiologia do Departamento de Morfologia e Patologia Básica da Faculdade de Medicina de Jundiaí (FMJ), Jundiaí/SP.

\section{Endereço para correspondência:}

Lais Aparecida Branco Zanchetta - Rua Zuferey no 241 - Jardim Pitangueiras I, Jundiaí-SP - CEP 13.202-420. Tel.: (15) 99686-1774, e-mail: laiszancheta@gmail.com

\section{RESUMO:}

Introdução: A psoríase é uma doença crônica, recorrente, imuno-mediada que afeta principalmente a pele, mas que quando acomete as articulações denomina-se Artrite Psoriásica. Na artrite psoriásica, o processo inflamatório articular é mediado por neutrófilos e linfócitos, resultando em remodelamento tecidual e deformidades. As lesões se iniciam após dano ao epitélio, levando à ativação da resposta imunológica e à produção de citocinas como o TNF-alfa, IL-1beta e IL-6. Em conjunto com citocinas produzidas por linfócitos TCD4+, essas citocinas amplificarão a resposta inflamatória local. A artrite psoriásica é tratada com uma combinação de drogas anti-inflamatórias, como o metotrexato e imunobiológicos. Porém, evidências recentes demonstraram que a metformina, utilizada para tratamento de doenças metabólicas, modula o processo inflamatório, alterando a produção de citocinas inflamatórias por células do sistema imunológico. Objetivo: Avaliar os efeitos da metformina na função inflamatória de neutrófilos e células mononucleares do sangue periférico de pacientes com artrite psoriásica. Materiais e Métodos: Para os experimentos, foi coletado o sangue periférico de pacientes com diagnóstico de Artrite Psoriásica $(n=15)$, sem uso de Metformina, atendidos no Ambulatório de Reumatologia da FMJ, de ambos sexos. Assim como de 15 indivíduos saudáveis (controles), sem comorbidades e sem uso de medicamento anti-inflamatório nos últimos 15 dias. Células mononucleares do sangue periférico (CMSPs) e células polimorfonucleares (PMNs) foram isoladas e mantidas in vitro sem tratamento ou tratadas com metformina em diferentes concentrações. Após o tratamento, as células foram estimuladas com LPS ou fitohemaglutinina por 48 horas e os sobrenadantes de cultura utilizados para a dosagem de citocinas (TNF-alfa, IL-1beta, IL-6, IL-10, IFN-gama, IL-17, IL-22 e IL-4) por ELISA. Resultados: Até o momento, foram obtidos resultados preliminares relacionados às padronizações de técnicas (culturas e ELISAs), que serão utilizados para a conclusão do projeto. Também foram coletadas amostras de sangue, com realização de cultura, de 15 pacientes com artrite psoriásica (com armazenamento dos sobrenadantes para dosagem de citocinas). Conclusão: Não foi possível obter resultados para conclusão do projeto, pois as atividades foram interrompidas (março de 2020) devido a pandemia do SARS-CoV-2. Medidas proibiram o acesso dos alunos aos laboratórios da FMJ, e dessa forma impediram a continuidade do projeto (coleta de sangue dos indivíduos controle, coleta das informações de prontuários dos pacientes com artrite psoriásica e realização dos ELISAs). Esperamos que assim que essas medidas sejam relaxadas, retomemos as atividades para a finalização do projeto inicialmente proposto.

Palavras-Chave: Psoríase, artrite psoriásica, células mononucleares do sangue periférico, neutrófilos, citocinas. 


\title{
AVALIAÇÃO DOS EFEITOS DA PREGABALINA NA PROLIFERAÇÃO E INVASIVIDADE DA LINHAGEM CELULAR DE CÂNCER DE PRÓSTATA (LNCaP)
}

\author{
Letícia Buschinelli Strutz ${ }^{1}$, Nilva K. Cervigne Furlan², Taize Machado Augusto ${ }^{3}$.
}

1. Graduando do curso de Medicina; Faculdade de Medicina de Jundiaí

2. Professora Adjunta da Disciplina de Hematologia do Departamento de Clínica Médica da Faculdade de Medicina de Jundiaí (FMJ), Jundiaí/SP.

3. Professora Adjunta da Disciplina de Hematologia do Departamento de Clínica Médica, Faculdade de Medicina de Jundiaí (FMJ), Jundiaí/SP.

\section{Endereço para correspondência:}

Letícia Buschinelli Strutz - R. Francisco Telles, no 84 - Vila Arens, Jundiaí-SP - CEP 13202-550. Tel.: (11) 993178481, e-mail: lestrutz@gmail.com.

\section{RESUMO:}

Introdução: A glândula prostática é um órgão masculino alvo de várias afecções, sendo as mais comuns as prostatites, neoplasias prostáticas benignas e malignas. Por esta razão, há grande motivação para estudos que se referem aos mecanismos de regulação de seu crescimento e de sua fisiologia, através de investigações em modelos animais e modelos in vitro. Existem diversas linhagens estabelecidas derivadas de câncer de próstata humano descritas na literatura como PC3, DU145 e $\mathrm{LNCaP}$, sendo as duas primeiras insensíveis ao andrógeno. Estudos demonstraram, pela primeira vez, que os canais de cálcio voltagem dependentes de baixa voltagem e a disponibilidade de cálcio estão intimamente associados a proliferação da linhagem LNCaP in vitro. Estes estudos foram conduzidos com a modulação de fatores que dirigem os processos mitogênicos como: fator de crescimento epidermal (EGF), condições alteradas de soro e testosterona em cultura. Neste contexto, a pregabalina (LYRICA - Pfizer) foi inserida, uma droga com ação análoga ao GABA utilizada, principalmente, para o tratamento de dor neuropática, epilepsias, ansiedade e fibromialgia. Ela é capaz de se ligar na subunidade $\alpha 2 \delta$ (tipo 1) dos canais de cálcio voltagem dependentes atenuando a entrada de cálcio nas células neuronais. Objetivo: A partir das informações levantadas pela avaliação dos efeitos da pregabalina, espera-se verificar os efeitos desta droga na capacidade de bloquear os canais de cálcio voltagem dependente das células $\mathrm{LNCaP}$. Para isto, o estudo verificará se determinada concentração do fármaco são capazes de diminuir e/ou bloquear a proliferação e invasividade celular desta linhagem em cultura. Materiais e Métodos: a linhagem LNCaP será tratada com concentrações variadas do fármaco pregabalina $(30 \mu \mathrm{g} / \mathrm{ml} ; 150 \mu \mathrm{g} / \mathrm{ml} ; 300 \mu \mathrm{g} / \mathrm{ml})$. Os experimentos serão conduzidos em paralelo com a diminuição da proliferação observada na ausência de soro fetal bovino (SFB). A capacidade invasiva será avaliada através de teste que verifica a potencialidade de migração celular (Scratch test). Genes envolvidos com aspectos metastáticos serão avaliados, dentre eles a MMP-2 e a HPSE-1. Resultados: $O$ treinamento em laboratório foi realizado inicialmente com uma linhagem em passagem celular muito alta, acarretando em nenhuma resposta aos experimentos iniciais com o tratamento. Nova linhagem com passage mais baixa foi adquirida. O cronograma para os novos experimentos estava montado e foi interrompido pela paralisão devido a pandemia da COVID-19. Conclusões: O treinamento em laboratório e cultura de células foi muito satisfatório e as etapas seguintes estavam progredindo com sucesso e serão retomadas com a normalização das atividades.

Palavras-Chave: próstata, pregabalina, receptor de andrógeno, heparanase. 


\section{AVALIAÇÃO DOS EFEITOS DE COMPONENTES DE BIOFILME FORMADO POR CANDIDA ALBICANS SOBRE AS FUNÇÕES EFETORAS DE NEUTRÓFILOS E MACRÓFAGOS}

Pedro Mello Rodrigues ${ }^{1}$, Clara Andrade Prado Teixeira ${ }^{1}$, Luiz Felipe Veronez Bonadiman Paulino', Ana Lúcia Bergamasco Galastri², Ronei Luciano Mamoni³ .

1. Graduando do curso de Medicina; Faculdade de Medicina de Jundiaí

2. Técnica de Laboratório (Colaborador) da Disciplina de Microbiologia do Departamento de Morfologia e Patologia Básica da Faculdade de Medicina de Jundiaí (FMJ), Jundiaí/SP.

3. Professor Adjunto da Disciplina de Imunologia do Departamento de Morfologia e Patologia Básica, Faculdade de Medicina de Jundiaí (FMJ), Jundiaí/SP.

\section{Endereço para correspondência:}

Pedro Mello Rodrigues - Alameda Mar Tirreno 63, Alphaville, Barueri-SP - CEP 06471-004. Tel.: (11)99893871-0, e-mail: pmr020698@gmail.com.

\section{RESUMO:}

Introdução: A formação de biofilmes por micro-organismos em apetrechos médicos (cateteres principalmente) representa um grande problema de saúde para indivíduos hospitalizados. Os biofilmes são formados como forma de resistência dos micro-organismos a antimicrobianos ou como mecanismo de escape do sistema imunológico, evitando o acesso das células que compõe esse sistema aos microorganismos. Candida albicans é o principal fungo encontrado em biofilmes, e infecções sistêmicas originadas em biofilmes apresentam taxa de mortalidade elevada. Dentre os componentes celulares do sistema imunológico inato responsáveis pela resposta contra fungos destacam-se os neutrófilos e macrófagos, efetores de fagocitose e de produção de espécies reativas de oxigênio (ROS) capazes de destruir as células fúngicas. Neutrófilos e macrófagos também participam da resposta inflamatória, e na atração de outras células do sistema imunológico para o local da infecção, pela produção de citocinas e quimiocinas inflamatórias. Embora a formação de biofilmes represente um mecanismo de escape importante do sistema imunológico, poucos estudos demonstram os efeitos dos componentes do biofilme formado por $C$. albicans sobre as funções de neutrófilos e macrófagos. Objetivo: O objetivo deste trabalho é avaliar os efeitos de componentes de matriz e componentes solúveis de biofilme de C. albicans sobre a função de neutrófilos humanos e macrófagos derivados de células THP-1. Materiais e Métodos: Neutrófilos, isolados do sangue de 10 indivíduos saudáveis, e macrófagos derivados de células THP-1, serão expostos a componentes de biofilme formado por $C$. albicans in vitro e depois avaliados quanto à capacidade de produzir citocinas pró-inflamatórias e anti-inflamatórias (por meio de ELISA), assim como quanto à produção de ROS. Resultados Parciais: No período que compreende 0 relatório foram desenvolvidas atividades de treinamento e padronização das metodologias que serão aplicadas no projeto, conforme previsto no cronograma. A discussão e as conclusões serão elaboradas após a conclusão dos experimentos previstos. Conclusão: Infelizmente, ainda não foi possível concluir os experimentos propostos no projeto original, devido à interrupção das atividades (março de 2020) em decorrência das medidas adotadas frente à pandemia de COVID-19 (causada pelo SARS-CoV-2), que proibiram o acesso dos alunos de graduação aos laboratórios da FMJ, e dessa forma impediram a continuidade do projeto. Esperamos que assim que o acesso aos laboratórios da Instituição seja permitido aos alunos de graduação, retomemos as atividades para a finalização do projeto proposto.

Palavras-Chave: Candida albicans, Biofilme, Neutrófilos, Macrófagos. 


\title{
CARACTERÍSTICAS CLÍNICAS DAS QUEDAS EM IDOSOS FRÁGEIS INTERNADOS EM ENFERMARIA DE PSICOGERIATRIA
}

\author{
Fernanda de Oliveira Ahn'1, Ivan Aprahamian².
}

1. Graduando do curso de Medicina; Faculdade de Medicina de Jundiaí

2. Professor Dr. Ivan Aprahamian (Adjunto), da Disciplina de Geriatria do Departamento de Clínica Médica, Faculdade de Medicina de Jundiaí (FMJ), Jundiaí/SP.

\section{Endereço para correspondência:}

Fernanda de Oliveira Ahn - R. Daniel Paulo Nasser, no 220 - Bairro Torres de São José, Jundiaí-SP CEP 13214-540. Tel.: (11) 986048096, e-mail: fenanda.ahn@gmail.com

\section{RESUMO:}

A fragilidade é uma síndrome que ainda não possui um consenso diagnóstico homogêneo, sendo caracterizada por um conjunto de fatores, tais como diminuição de força, de resistência e declínio gradual das funções fisiológicas e homeostáticas. Ela acomete principalmente idosos e envolve diversos sistemas, como o neurológico, endócrino, imunológico e musculoesquelético. Dessa forma, a fragilidade torna o idoso mais predisposto a eventos adversos e até mesmo incapacitantes, como quedas e possíveis fraturas decorrentes destas. Em virtude do risco de eventos adversos, instrumentos diagnósticos vêm sendo desenvolvidos para detectar precocemente os indivíduos frágeis e pré-frágeis, através de escalas simples e rápidas de rastreio, tais como a FRAIL, e instrumentos robusto para diagnóstico como o Frailty Index (Índice de fragilidade). Um grupo pouco estudado e com potencial risco para a fragilidade são os idosos portadores de doenças mentais graves. Estes possuem frequentemente polifarmácia, múltiplas morbidades, pouca adesão terapêutica e apresentam frequentemente desfechos desfavoráveis com diversas etiologias, como as quedas. $O$ estudo das características das quedas em idosos frágeis é importante para a compreensão de fatores associados ao quadro de fragilidade nessa população específica. Esse estudo objetiva avaliar a associação entre quedas e fragilidade em idosos internados na enfermaria de psicogeriatria do Hospital Everett do complexo Cambridge Health Alliance, em Everett, Massachusetts. Adicionalmente, avaliou-se a associação de diversas variáveis independentes com a fragilidade nesses pacientes.

Palavras-Chave: fragilidade; doença psiquiátrica; hospitalização; quedas; idosos. 


\title{
CONSTELAÇÃO FAMILIAR: A NOVA PIC DO SUS NAS UNIDADES DE SAÚDE EM JUNDIAÍ
}

\author{
Beatriz Ritzmann Ferraz'1 Lívia Oliveira Rosa'1, Camila Gonçalo Mialhe²
}

1. Graduanda do curso de Medicina; Faculdade de Medicina de Jundiaí

2. Professora Adjunta das disciplinas de Políticas Públicas de Saúde/ Atenção Primária e Educação em Saúde do Departamento de Saúde Coletiva da Faculdade de Medicina de Jundiaí (FMJ), Jundiaí/SP.

\section{Endereço para correspondência:}

Beatriz Ritzmann Ferraz - R. Zuferey, oo 183 - Vila Arens, Jundiaí-SP - CEP 13202-420. Tel.: (19) 99176-4588, e-mail: biaritzmannferraz@gmail.com.

\section{RESUMO:}

Introdução: Constelação Familiar (CF) é um método que se utiliza da abordagem fenomenológica, sistêmica e energética visando reconhecer a gênese de questões trazidas pelo indivíduo, buscando atingir crescimento e cura através de uma reorientação de seus movimentos na vida. A CF foi estruturada por Bert Hellinger e vem sendo utilizada no mundo inteiro. Sua eficácia tem sido reconhecida em vários cenários, inclusive no campo da saúde mental. Atualmente figuram cerca de 29 modalidades de Práticas Integrativas e Complementares (PIC) no sistema de saúde pública no Brasil, e a CF foi incluída no Sistema Único de Saúde (SUS) por meio da Portaria no. 718 de 21 de março de 2018. Objetivo: Considerando que a CF é uma prática inovadora, recentemente incluída no sistema público de saúde no Brasil, o objetivo da pesquisa foi realizar um estudo exploratório para verificar o conhecimento de profissionais do SUS-Jundiaí acerca da CF. Materiais e Métodos: Foi realizado um estudo exploratório quanti-qualitativo em unidades de saúde que oferecem atendimentos com as PIC e em unidades que não oferecem tais atendimentos. Resultados: Dos 20 participantes que preencheram o questionário online, a maioria declarou ser do sexo feminino $(n=16 ; 80 \%)$ e a maior parte dos respondentes exerce cargos variados dentro das unidades de saúde em que atuam. A maioria declarou saber o que era a CF $(n=11 ; 55 \%) ; 16(80 \%)$ desconhecem que a CF é oferecida pelo SUS desde 2018; 12 (60\%) desconhecem qual seria o caminho para implantar PICs na unidade de saúde; $15(75 \%)$ desconhecem se a unidade de saúde recebeu orientações para implantação da CF e 19 (95\%) desconhecem qualquer previsão da oferta de CF na unidade de saúde. Sobre a primeira questão aberta que abordava o conceito de CF, os participantes apresentaram "ideias convergentes" e "divergentes" em relação ao referencial adotado pelo Ministério da Saúde. Na segunda questão aberta, a pergunta versava sobre como a CF poderia contribuir com a área da saúde, e, das respostas, emergiram dois eixos temáticos: "auxiliando os usuários a lidarem com seus sentimentos" e "auxiliando os usuários a lidarem com as doenças". Conclusão: Conclui-se que, embora a CF seja uma PIC reconhecida e seu uso na rede pública de saúde seja encorajado pelas autoridades sanitárias brasileiras, os participantes desta pesquisa apresentaram conhecimentos incipientes sobre o tema.

Palavras-Chave: Saúde Mental, Atenção Primária à Saúde, Sistema Único de Saúde. 


\section{DIABETES MELLITUS TIPO 2: DETERMINANTES SOCIAIS NA ADESÃO AO AUTOCUIDADO EM IDOSOS}

Bruna Porredon Poletto Alves ${ }^{1}$, Sofia Moretti Carneiro ${ }^{1}$, Maria José Martins Duarte Osis ${ }^{1}$

1. Faculdade de Medicina de Jundiaí/FMJ.

\section{Endereço para correspondência:}

Bruna Porredon Poletto Alves. Rua Zufferey, n 183 apto 301, Edifício Julia. Bairro Jardim Pitangueiras I. Jundiaí-SP. CEP 13202-420. Telefone: (11) 99904-9059. E-mail: brunappoletto@gmail.com

Introdução: Diabete Mellitus (DM) tipo 2 é uma das doenças crônicas não transmissíveis mais prevalentes no Brasil, sobretudo entre pessoas idosas. Isto torna relevante a busca de maior adesão dos portadores ao tratamento. Objetivos: Identificar a adesão ou não ao tratamento medicamentoso e a atividades de autocuidado entre idosos com DM 2 atendidos em Unidades Básicas de Saúde (UBS) de Jundiaí, SP; e verificar se existem características socioeconômicas e/ou do tratamento associadas a essa adesão. Métodos: Estudo transversal com 56 pessoas de 60 anos ou mais, portadoras de DM 2, em acompanhamento em duas UBS de Jundiaí. O tamanho amostral calculado inicialmente foi de 77 participantes, porém, a coleta de dados precisou interrompida antes que se alcançasse esse número, devido às restrições impostas pela pandemia. Os participantes responderam um conjunto de perguntas que incluiu a sua caracterização, a escala Medida de Adesão ao Tratamento (MAT) e o Questionário de Atividades de Autocuidado com o Diabetes (QAD). Resultados: A maioria dos participantes tinha de $60-70$ anos $(70,8 \%)$, declarou-se do sexo feminino $(69,6 \%)$, de pele branca $(69,6 \%)$, com ensino fundamental 1 completo $(60,7 \%)$, casados $(60,7 \%)$ e com renda familiar de $1-2$ salários mínimos (66,7\%). Sobre o tratamento para diabetes, 75\% usavam apenas comprimidos; $91,1 \%$ disseram que ninguém os auxiliava a controlar a medicação; 89,3\% não participavam de atividades promovidas pela UBS e 71,4\% não praticavam atividade física. As principais dificuldades para seguir o tratamento proposto foram "ter uma alimentação saudável" $(51,8 \%)$ e "realizar atividade física" $(25 \%)$. A grande maioria dos participantes apresentou alta adesão ao tratamento medicamentoso (92,9\%), com escore médio >= 5 na escala MAT; e também às atividades de autocuidado (83,9\%), com escore $>0 u=40$ no QAD. Na análise bivariada verificou-se que apenas a variável número de pessoas que contribuem para renda familiar esteve associada ao escore de autocuidado. Conclusão: Na amostra estudada a adesão ao tratamento medicamentoso e a atividades de autocuidado com o diabetes foi alta, com proporções acima de $80 \%$. Isto, de modo geral, foi coerente com a literatura disponível, e pode estar associado a um adequado trabalho de educação em saúde e monitoramento desenvolvido pelas UBS em que os participantes eram acompanhados. Entretanto, nossas conclusões ainda são limitadas pela impossibilidade de ter o número necessário de participantes e realizar todas as análises propostas no projeto de pesquisa. Por isto, consideramos fundamental, assim que possível, incluir mais participantes no estudo e completar a análise.

Descritores de assunto: Diabetes Mellitus Tipo 2; Adesão ao Tratamento Medicamentoso; Autocuidado; Determinantes sociais da saúde; Pessoas idosas. 


\title{
DISTÚRBIOS DO SONO EM PACIENTES COM ARTRITE PSORIÁTICA DO AMBULATÓRIO DE REUMATOLOGIA DA FACULDADE DE MEDICINA DE JUNDIAÍ
}

\author{
Mariana Castanho Risso ${ }^{1}$, Giovanna de Castro Picelli ${ }^{1}$, Waldenise Cossermelli2
}

1. Graduando do curso de Medicina; Faculdade de Medicina de Jundiaí

2. Professor Orientador da Disciplina de Reumatologia do Departamento de Reumatologia, Faculdade de Medicina de Jundiaí (FMJ), Jundiaí/SP.

\section{Endereço para correspondência:}

Mariana Castanho Risso - R. Visconde de Taunay, no 206, apto 510 - Vila Arens, Jundiaí-SP - CEP 13202-540. Tel.: (11)98688-4350, e-mail: marianacrisso97@gmail.com.

RESUMO: Os distúrbios do sono são, atualmente, um grande problema de saúde pública no Brasil, devido a sua elevada incidência, difícil tratamento e identificação da causa. Pacientes portadores de doenças reumatológicas, em grande parte dos casos, apresentam alterações do estado do sono, o que ocasiona redução da qualidade de vida, naturalmente já reduzida pelo processo inflamatório crônico da própria enfermidade inicial. Todavia, pouco se sabe sobre a associação entre a doença reumática artrite psoriática e a incidência de distúrbios do sono. Sendo assim, este estudo visou identificar e descrever a existência de patologias do sono em pacientes portadores de artrite psoriática assim como verificar uma possível associação de distúrbios do sono com síndrome metabólica nestes indivíduos. Para isso, foram estudados 31 pacientes com artrite psoriática do Ambulatório de Reumatologia da Faculdade de Medicina de Jundiaí (FMJ) a partir de 3 questionários de avaliação de sono: Questionário de Pittsburgh (PSQI), Escala de Epworth (EPW) e Questionário de Berlim. Além disso, utilizou-se de um questionário sociodemográfico para identificação de variáveis diversas, inclusive da presença de síndrome metabólica. Em média, constatou-se a presença de distúrbios do sono em $54,83 \%$ dos pacientes estudados ( $64,5 \%$ no PSQI, $51,6 \%$ no EPW e $48,4 \%$ no Berlim) e em torno de $70 \%$ de distúrbios do sono nos pacientes com diagnóstico simultâneo de síndrome metabólica e artrite psoriática. Outra variável importante analisada foi a associação de patologias do sono em paciente com hipertensão e artrite psoriática, em torno de $83,3 \%$ pelo PSQI, 58,3\% no EPW e 75,0\% no Berlim. A partir desses resultados, é notável que os distúrbios do sono são comuns em pacientes com diagnóstico de artrite psoriática, sendo ainda mais significativos quando estes apresentam diagnóstico de hipertensão ou síndrome metabólica concomitantemente. Dessa forma, essa patologia demanda maior atenção na prática clínica e busca de terapêutica ideal e completa, além de exigir controle simultâneo da artrite, do sono, da hipertensão, da dislipidemia e da obesidade para que não exista influência de umas sobre as outras, levando a um risco cardiovascular maior, piora da dor e do sono.

Palavras-chave: Distúrbios do sono; Artrite Psoriática; Privação do sono. 


\section{DOENÇAS DERMATOLÓGICAS PREVALENTES EM UM HOSPITAL INFANTIL DA REDE PÚBLICA DE SÃO PAULO}

Giovanna de Castro Picelli', Mariana Castanho Risso', Geovane Ribeiro dos Santos², Jacqueline Campoi Calvo Lopes Pinto ${ }^{3}$, Clóvis Antonio Lopes Pinto4.

1. Graduando do curso de Medicina; Faculdade de Medicina de Jundiaí

2. Colaborador e Técnico do Laboratório de Patologia do Departamento de Patologia, Faculdade de Medicina de Jundiaí (FMJ), Jundiaí/SP.

3. Professora colaboradora da Disciplina de Dermatologia do Departamento de Clínica Médica, Faculdade de Medicina de Jundiaí (FMJ), Jundiaí/SP.

4. Professor adjunto da Disciplina de Patologia do Departamento de Patologia, Faculdade de Medicina de Jundiaí (FMJ), Jundiaí/SP.

\section{Endereço para correspondência:}

Giovanna de Castro Picelli - R. Zuferey, o 155, apartamento 201 bloco 6 - Vila Arens, Jundiaí-SP CEP 13202-420. Tel.: (19) 99822-0521, e-mail: giovannapicelli@hotmail.com

\section{RESUMO:}

Introdução: A pele é o maior órgão do corpo humano, tendo muitas funções importantes, tais como a proteção contra agentes externos, sensibilidade tátil e térmica, além do controle da temperatura basal, favorecendo trocas entre meio externo e interno. As doenças dermatológicas apresentam grande incidência nas consultas pediátricas, dada a maior fragilidade do tegumento infantil em relação ao do adulto, devido às diferenças anatômicas e fisiológicas. Sabe-se que as enfermidades cutâneas provocam grande grau de constrangimento, afetando direta e indiretamente o desenvolvimento psicossocial e econômico das crianças e de seus responsáveis. Objetivo: o presente estudo tem como objetivo identificar as doenças dermatológicas mais prevalentes em pacientes de 0 a 12 anos no Hospital Infantil Cândido Fontoura em São Paulo - SP, além de identificar os impactos psicossociais da doença na criança e nos seus responsáveis, a fim de propor medidas para minimizar estes impactos e contribuir para uma melhor qualidade de vida destes. Metodologia: Foi utilizado, como instrumento de análise, os dados extraídos de um questionário com variáveis demográficas e clínicas, aplicado a 226 pacientes entre 0e 12 anos, com faixa etária média de 5,98 anos, entre setembro/2019 e março/2020, neste hospital da rede pública de São Paulo - SP no Ambulatório de Dermatologia. Por meio de um estudo descritivo, transversal e quantitativo, as variáveis demográficas e clínicas foram correlacionadas com os impactos psicossociais gerados pela doença na criança e nos seus responsáveis. Resultados e Conclusão: Identificou-se que a principal queixa referida foi a de 'Lesões de pele' - conforme as próprias palavras do paciente - sendo que que a maioria das crianças questionadas apresentavam comorbidades prévias, tais como rinite alérgica e bronquite. Além disso, os sinais e/ou sintomas descritos não impactavam diretamente no comportamento da maioria das crianças, demonstrando que a dermatose afeta psicologicamente mais os responsáveis. Por fim, o diagnóstico mais incidente foi o de Dermatite atópica, seguido de Molusco Contagioso e diagnósticos a esclarecer.

Palavras-Chave: Doenças dermatológicas, crianças, qualidade de vida. 


\section{EPIDEMIOLOGIA DA FEBRE MACULOSA NA REGIÃO METROPOLITANA DE JUNDIAÍ, NO ESTADO DE SÃO PAULO E NO BRASIL}

Brunna Taborda Saragiotto', Fernanda Ahn'1, Juliana Quero Reimão²

1. Graduando do curso de Medicina; Faculdade de Medicina de Jundiaí

2. Professora Adjunta da Disciplina de Parasitologia do Departamento de Morfologia e Patologia Básica da Faculdade de Medicina de Jundiaí (FMJ), Jundiaí/SP.

\section{Endereço para correspondência:}

Juliana Quero Reimão - R. Francisco Teles, no 250 - Vila Arens II, Jundiaí-SP - CEP 13202-550. Tel.: (11) 3395-2100, e-mail: juliana_reimao@yahoo.com.br.

\section{RESUMO:}

Introdução: A Febre Maculosa (FM) é uma doença infecciosa febril aguda, causada por bactérias Gram-negativas, intracelulares obrigatórias do gênero Rickettsia, que são transmitidas por carrapatos do gênero Amblyomma, cujo reservatório são animais como capivaras e cavalos. A FM possui sintomas inespecíficos como febre alta, mialgias, cefaleia, mal-estar generalizado e hipertermia das conjuntivas, o que leva ao seu subdiagnóstico. O Brasil é endêmico para FM e devido à sua alta mortalidade, a notificação compulsória desse agravo ocorre desde 2007. Objetivo: Analisar os dados epidemiológicos sobre a incidência de FM na Região Metropolitana(RM) de Jundiaí (Cabreúva, Campo Limpo Paulista, Itupeva, Jarinu, Jundiaí, Louveira e Várzea Paulista), no Estado de São Paulo (ESP) e no Brasil. Materiais e Métodos: Foi realizado um estudo epidemiológico descritivo, com base nos casos de FM notificados pelas fichas de investigação disponíveis no Sistema de Informação de Agravos de Notificação (SINAN) entre 2007 e 2017. Resultados: Os dados obtidos indicaram que a FM se encontra em expansão, com um aumento de 162\% no número de casos no Brasil no período de 2007 a 2017 em comparação com a década anterior, e de $167 \%$ no ESP. Altas taxas de incidência foram observadas na RM de Jundiaí, com destaque para o ano de 2016, em que a taxa de incidência alcançou um pico de 1,28 casos por 100.000 habitantes, e com uma média de 0,34 casos por 100.000 habitantes ao longo do período de 2007 a 2017. Já no ESP, a taxa de incidência média observada no período estudado foi de 0,18 casos por 100.000 habitantes, enquanto no Brasil foi de 0,08 casos por 100.000 habitantes. Os indivíduos mais acometidos foram homens jovens de etnia branca. Os possíveis motivos para tais achados são discutidos no presente trabalho. Conclusão: De acordo com os dados obtidos, conclui-se que a FM é uma doença em expansão, que não se restringe apenas às regiões rurais. Assim, faz-se necessário aumentar e otimizar as estratégias de controle de vetores nas áreas de risco, além de disseminar informações alertando aos serviços de saúde sobre a necessidade de intensificar as ações de prevenção primária contra a FM.

Palavras-Chave: Febre Maculosa, epidemiologia, Jundiaí. 


\section{EPIDEMIOLOGIA DOS ACIDENTES COM ANIMAIS PEÇONHENTOS NO ESTADO DE SÃO PAULO E NO MUNICÍPIO DE JUNDIAÍ}

Thamires Fernandes Pazetti ${ }^{1}$, Pedro Dresch de Michel1 ${ }^{1}$, Juliana Quero Reimão².

1. Graduando do curso de Medicina; Faculdade de Medicina de Jundiaí

2. Professora Adjunta da Disciplina de Parasitologia do Departamento de Morfologia e patologia Básica da Faculdade de Medicina de Jundiaí (FMJ), Jundiaí/SP.

\section{Endereço para correspondência:}

Juliana Quero Reimão - R. Francisco Teles, № 250 - Vila Arens II, Jundiaí-SP - CEP 13202-550. Tel.: (11) 3395-2100, e-mail: juliana_reimao@yahoo.com.br.

\section{RESUMO:}

Introdução: Os animais peçonhentos são discriminados por possuírem estruturas para inocular diretamente toxinas em outros organismos. No Brasil, os acidentes com animais peçonhentos são subnotificados e os bancos de dados são limitados a serpentes, escorpiões, aranhas, lagartas e abelhas. Dentre os animais peçonhentos, os escorpiões são os animais de maior importância clínica dado sua morbidade e mortalidade. $O$ avanço do escorpionismo no país apresentou gravidade crescente em todas as regiões, com notificações em muitos municípios, principalmente nas áreas urbanas. Atualmente, o maior número de casos de acidentes com animais peçonhentos corresponde ao escorpionismo. Devido à gravidade e magnitude do envenenamento que esses acidentes causam, decidiu-se realizar um estudo epidemiológico, com foco nos acidentes causados por escorpiões, descrevendo o perfil dos casos no município de Jundiaí, com o propósito de avaliar e reportar a situação do município em relação ao Estado de São Paulo. Objetivo: Analisar as características epidemiológicas dos acidentes com animais peçonhentos, com especial ênfase em escorpionismo, no Estado de São Paulo (ESP) e no município de Jundiaí (MJ) no período de 2007 a 2017. Materiais e Métodos: Foi realizado estudo retrospectivo, quantitativo, descritivo-analítico dos indicadores epidemiológicos obtidos a partir das fichas de investigação de acidentes por animais peçonhentos, os quais foram acessados através do Sistema de Informação de Agravos de Notificação (SINAN). Resultados: Foram notificados 222.302 casos de acidentes por animais peçonhentos no ESP e 1.571 no MJ no período de 2007 a 2017. Deles, 116.705 e 509 notificações corresponderam a acidentes causados por escorpiões no ESP e no MJ, respectivamente. O sexo mais acometido foi o masculino, representando $60 \%$ dos casos. No MJ, as faixas etárias de 20-39 e 40-59 foram responsáveis por 69\% dos acidentes e a escolaridade das vítimas foi ignorada em $69 \%$ das notificações. Houve evolução para cura em $93,63 \%$ e $83,3 \%$ dos casos no ESP e no MJ, respectivamente. Conclusão: Notou-se um aumento gradual do número de acidentes por escorpiões no ESP e no MJ, o que demanda o desenvolvimento de novas políticas públicas de saúde visando controlar a população desses aracnídeos pelo risco que apresentam para a saúde humana. Faz-se necessário também, intensificar as ações de prevenção por meio da educação permanente em saúde, compartilhando informações sobre os fatores de risco envolvidos e apontar ações para precaver-se contra os acidentes com escorpiões.

Palavras-Chave: Animais peçonhentos, Escorpiões, Epidemiologia 


\title{
ESTUDO COMPARATIVO ENTRE OS EFEITOS DAS ENTEROTOXINAS ESTAFILOCÓCICAS E DO LIPOLISSACARIDEO DE ESCHERICHIA COLI SOBRE AS PROPRIEDADES FUNCIONAIS DE NEUTRÓFILOS
}

\author{
Henrique Herrera Piguin ${ }^{1}$, Ana Luisa Marossi Justiniano ${ }^{1}$, Gustavo Dias Teixeira ${ }^{1}$,
} Ana Paula Ferreira-Duarte²; Ivani Ap de Souza ${ }^{3}$.

1. Graduando do curso de Medicina; Faculdade de Medicina de Jundiaí

2. Doutoranda da Pós-graduação em Ciências da Saúde da Faculdade de Medicina de Jundiaí (FMJ), Jundiaí/SP.

3. Professor Adjunto da Disciplina de Fisiologia Humana do Departamento de Biologia e Fisiologia, Faculdade de Medicina de Jundiaí (FMJ), Jundiaí/SP.

\section{Endereço para correspondência:}

Nome do Autor: Henrique Herrera Piguin - R. Monte Alegre, no 33 - Santo Antônio, São Caetano do Sul-SP - CEP - 09531-110. Tel.: (11) 4335-1720. E-mail: henriqueherrerap@uol.com.br

\section{RESUMO:}

Introdução: A sepse é uma doença inflamatória sistêmica que atinge cerca de 17 milhões de pessoas por ano em todo o mundo. É a principal causa de admissão e morte de pacientes nas unidades de terapia intensiva. A sepse por bactérias gram-positivas apresenta maior índice de mortalidade do que a sepse por bactérias gram-negativas. Uma inadequada mobilização de neutrófilos em quadros de sepse grave é a principal causa de morte. Os efeitos patológicos do Staphylococcus aureus se devem à produção e a secreção das enterotoxinas estafilocócicas (SEs). Nossos estudos têm demonstrado que neutrófilos humanos incubados com SEs apresentam redução nas propriedades funcionais de quimiotaxia e adesão via ativação do MHC classe II. No entanto, poucos estudos comparam os efeitos de produtos de bactérias gram-negativas com os de bactérias gram-positivas, nas propriedades funcionais de neutrófilos. Objetivo: Comparar os efeitos das SEs com os efeitos do Lipopolissacarídeo bacteriano (LPS) de Escherichia coli sobre as propriedades funcionais de neutrófilos isolados do sangue humano. Materiais e Métodos: Amostras $(40 \mathrm{ml})$ de sangue foram coletadas de voluntários saudáveis após aprovação do comitê de ética em pesquisa da FMJ (Protocol No 61370616.3.0000.5412). As amostras de sangue foram colocadas em solução isotônica de Percoll e após centrifugação eritrócitos e granulócitos foram aspirados e submetidos a lise isotônica. A seguir as células (98\% neutrófilos), ressuspensas na concentração de $4 \times 10^{6}$ células $/ \mathrm{ml}$, foram submetidas a incubação in vitro com SEA, SEB (100 ng/ml; $2 \mathrm{~h})$ ou LPS $(1 \mu \mathrm{g} / \mathrm{ml})$. Os ensaios de adesão foram realizados em placas previamente revestidas com as moléculas de adesão VCAM-1 e ICAM-1 e os ensaios de quimiotaxia foram realizados em câmara de Boyden, ambos na presença de interleucina-8 (IL-8). Resultados: Nossos resultados demonstraram que o LPS, assim como as SEs dos tipos A (SEA) e $B$ (SEB) é capaz de induzir redução das propriedades funcionais de quimiotaxia e adesão em neutrófilos humanos. Incluímos também como objetivo analisar a participação do MHC classe II nos efeitos do LPS em neutrófilos. No entanto, devido as medidas de isolamento social em função da pandemia do COVID-19 estas etapas foram interrompidas. Conclusão: A incubação de neutrófilos do sangue humano com LPS resulta em redução das propriedades funcionais de quimiotaxia e adesão destas células. No entanto, estudos adicionais serão necessários para esclarecer se o mecanismo pelo qual o LPS induz disfunção de neutrófilos se assemelha ou não aos mecanismos envolvidos nas ações das SEs nestas células.

Palavras-Chave: Neutrófilos, Sepse, toxinas bacterianas 


\section{ESTUDO DA UTILIZAÇÃO DE MATRIZES DE COLÁGENO E ELASTINA ASSOCIADO COM NANOHIDROXIAPATITA NO REPARO ÓSSEO}

Rafael Chagas Gusmão1, Ivan Moreira Mezzacapa², Marcelo Rodrigues da Cunha ${ }^{3}$

1. Autor; Graduando do Curso de Medicina; Faculdade de Medicina de Jundiaí.

2. Colaborador; Pós-Graduação da Faculdade de Medicina de Jundiaí (FMJ), Jundiaí/SP.

3. Orientador; Disciplina de Anatomia da Faculdade de Medicina de Jundiaí (FMJ), Jundiaí/SP.

\section{Endereço para correspondência:}

Rafael Chagas Gusmão - R. Zuferey, № 183, bloco 5, apartamento 202 - Jardim Pitangueiras, JundiaíSP - CEP 13202-420 Tel.: (11) 99276-2024, e-mail: rafaelchagasgusmao@gmail.com

\section{RESUMO:}

Introdução: Dentre as dificuldades na medicina contemporânea, a regeneração óssea tem sido objeto de estudos constantes devido aos altos índices de acidentes automobilísticos que resultam em fraturas com perda óssea acentuada. Frente a isso, os biomateriais se apresentam como uma opção para o tratamento de lesões ósseas visto as limitações do uso dos enxertos autólogos e dentre esses materiais, destacam-se as matrizes poliméricas pelas suas características estruturais que as tornam um scaffold para a adesão e crescimento celular. Objetivo: Analisar o processo de neoformação óssea através de enxertos de membranas poliméricas compostas de nanohidroxiapatita com colágeno e de elastina derivado do intestino e da cartilagem auricular bovina. Método: Foram utilizados 20 ratos machos Rattus norvegicus com 15 semanas de idade e submetidos ao procedimento cirurgico para criação de um defeito na tibia direita. Os animais foram separados em dois grupos sendo GI (controle, sem implante no defeito ósseo tibial) e GII (enxertado com membrana polimérica). Após seis semanas da cirurgia, os animais foram sacrificados e as áreas cirúrgicas na tíbia foram removidas para as análises macroscópicas, radiológicas e histológicas do processo de neoformação óssea do local cirúrgico. Resultados: $\mathrm{Na}$ análise macroscópica, ocorreu biocompatibilidade na área cirúrgica do Gll devido à ausência de processos infecciosos ou inflamatórios. Nas observações radiológicas, não houve fraturas adjacentes e também não se presenciou pontos de rarefação óssea que pudesse indicar algum processo inflamatório no sítio cirúrgico. Os resultados histomorfométricos indicam neoformação óssea partindo das margens do defeito e de natureza imatura e trabeculada, sendo em maior volume no Gll. Conclusão: Os biomateriais utilizados apresentaram biocompatibilidade com o tecido hospedeiro e proporcionaram estímulo ao processo de reparo ósseo podendo desta maneira, ser indicado na área da medicina regenerativa do tecido ósseo.

Palavras-Chave: Biomateriais, Tecido Ósseo, Regeneração Óssea. 


\section{ESTUDO DO EFEITO DO EXTRATO POLYPODIUM LEUCOTOMOS SOBRE AS VIAS DE RESPOSTA IMUNE EM LINHAGEM HUMANA DE MACRÓFAGOS}

Mariana S. Teixeira ${ }^{1}$, Luan Oenning², Lucilene S. Lopes², Pammela A. Lacerda², Carine Ervolino³, Taize M. Augusto ${ }^{2}$, Ronei Mamoni4 ${ }^{4}$ Nilva K. Cervigne ${ }^{2,5^{*}}$.

1. Graduando do curso de Medicina (4ํㅡㄹ Ano), Faculdade de Medicina de Jundiaí (FMJ), Jundiaí/SP.

2. Laboratório de Biologia Molecular e Cultura Celular, Faculdade de Medicina de Jundiaí (FMJ), Jundiaí/SP.

3. Departamento de Patologia, Faculdade de Ciências Farmacêuticas, Universidade Federal de Alfenas (UNIFAL), Alfenas/MG.

4. Laboratório de Imunologia, Departamento de Morfologia e Patologia Básica (Disciplina de Imunologia e Microbiologia), Faculdade de Medicina de Jundiaí (FMJ), Jundiaí/SP.

5. Departamento de Clínica Médica (Disciplina de Hematologia), Faculdade de Medicina de Jundiaí (FMJ), Jundiaí/SP.

*Autor correspondente: Nilva K. Cervigne - Rua Francisco Telles, o 95 - Vila Arens II, Jundiaí-SP CEP 13202-550. Tel: (11) 3395-2100 ext.2137, e-mail: nilvafurlan@g.fmj.br.

Introdução: O extrato fitoterápico Polypodium leucotomos (PL), rico em polifenóis, parece ter efeitos benéficos na saúde humana, especialmente no que diz respeito a sua atividade anti-inflamatória. Macrófagos funcionam como chaves de controle do sistema imunológico, mantendo o equilíbrio entre atividades pró e anti-inflamatórias, e desempenham importante papel no microambiente tumoral. A transformação neoplásica acarreta mudanças na produção local de citocinas. As células inflamatórias presentes no tecido tumoral podem contribuir para o desenvolvimento e manutenção do câncer, pela liberação de potentes mediadores solúveis que regulam a sobrevivência e proliferação celular, angiogênese, integridade genômica, remodelamento tecidual e o metabolismo. A compreensão do papel imune na patogênese dos cânceres e sua abordagem terapêutica representam grandes desafios na oncologia atual. Embora estudos anteriores tenham demonstrado que os polifenóis possuam propriedades anti-inflamatórias, até onde sabemos, uma pesquisa focada sobre o efeito direto de $P L$ sobre o fenótipo inflamatório de macrófagos nunca foi realizada. Objetivo: Investigar se o extrato polifenólico Polypodium leucotomos poderia influenciar a polarização de macrófagos como um "interruptor" metabólico, promovendo um estado anti-inflamatório, por meio de ensaios in vitro com a linhagem celular humana monocítica THP-1. Materiais e Métodos: As células THP-1 foram induzidas com PMA e ativadas com lipopolissacarídeos para polarização de fenótipo pró-inflamatório, anteriormente ou após incubação com o tratamento fitoterápico $P L$. Os dados dos testes in vitro foram sempre comparados com as células não tratadas com o fitoterápico (controle). Resultados: 0 fitoterápico $P L$ parece influenciar o fenótipo pró-inflamatório dos macrófagos polarizados, já que as populações tratadas (pré e pós-polarização) mostraram morfologia marcadamente distinta das populações polarizadas não tratadas com $P L$. No entanto, ainda precisamos aguardar as análises de expressão dos genes marcadores pró- (TNF, NO) e anti-inflamatórios (IL-10, Arg1, MRC1), em andamento, para delinearmos com clareza o papel desse fitoterápico na modulação desses processos inflamatórios da linhagem THP-1. Adicionalmente, a avaliação da capacidade funcional (fagocítica) dos macrófagos pró-inflamatórios demonstrou um número significativamente maior $(p<0.05)$ na quantidade de bactérias fagocitadas na cultura de macrófagos polarizados tratados com $P L$, quando comparado com o número de CFU detectado na cultura de macrófagos polarizados que não foram tratados com esse fitoterápico. Conclusão: Nossos dados sugerem que o fitoterápico $P L$ desempenha papel protetor para o fenótipo pró-inflamatório de macrófagos e estimula sua capacidade funcional fagocítica. A identificação de moléculas e mecanismos modulados mediante uso de fitoterápicos, e associados com a flexibilidade da resposta imune e vias inflamatórias, poderia fornecer bases para a terapêutica centrada na resposta do perfil imunológico dos pacientes oncológicos.

Palavras-Chave: Polypodium leucotomos, fitoterapia, THP-1, câncer, resposta imune, macrófagos. 


\section{ESTUDO IN VIVO DA APLICABILIDADE DE MATRIZES POLIMÉRICAS DE POLI (E-CAPROLACTONA) E POLI (HIDROXIBUTIRATO-CO-HIDROXIVALERATO) NO REPARO DE LESÕES CRANIANA}

Nicole Beatriz de Alcantara Ferreira Garrido, Marcelo Rodrigues da Cunha², Arnaldo Rodrigues Santos Junior ${ }^{3}$.

1. Graduando do curso de Medicina; Faculdade de Medicina de Jundiaí

2. Professor Prof. Dr. Marcelo Rodrigues da Cunha Adjunto da Disciplina de Anatomia do Departamento de Morfologia e Patologia Básica da Faculdade de Medicina de Jundiaí (FMJ), Jundiaí/SP.

3. Professor Prof. Dr. Arnaldo Rodrigues Santos Junior representante do Instituto de Ciências Naturais da Universidade Federal do ABC

\section{Endereço para correspondência:}

Nicole Beatriz de Alcantara Ferreira Garrido - Avenida Vigário João José Rodrigues, no 480 - Centro, Jundiaí-SP - CEP 13201-001 Tel.: (11) 988431016 e-mail: nicolebalcantara@gmail.com.

\section{RESUMO:}

A engenharia tecidual vem explorando o uso dos auto-enxertos e aloenxertos no tratamento de lesões com perda de massa óssea acentuada. Como alternativa, há também os biomateriais para o estímulo osteoregenerativo. Esses materiais, contudo, devem apresentar algumas características básicas como ser biofuncional, biodegradável, biocompatível, esterilizável e mimetizar algumas reações do tecido ósseo. Atendendo a estes requisitos, os polímeros vêm sendo usado nas terapias do reparo ósseo, destacando-se o Poli ( $\varepsilon$ - caprolactona) - PCL e o Poli(hidroxibutirato-co-hidroxivalerato) - PHBV pelo fato de serem facilmente processados além de funcionarem como um possível suporte para a adesão e proliferação celular. Sendo assim, o objetivo desse trabalho é avaliar a capacidade osteogênica da combinação de PCL e PHBV no reparo de defeitos produzidos experimentalmente na calota craniana de ratos. Serão utilizados 28 ratos (Rattus norvegicus, Wistar) machos com 15 semanas de idade e peso médio de $350 \mathrm{~g}$, separados nos seguintes grupos: grupo 1 (G1) sem preenchimento na lesão óssea (Grupo Controle); grupo 2 (G2) preenchido com matriz de PCL; grupo 3 (G3) com matriz de PHBV e o grupo 4 (G4) com blendas (PCL/PHBV). O sacrifício dos animais ocorrerá 8 semanas póscirúrgico do defeito experimental no crânio dos animais. As amostras das áreas cirúrgicas serão removidas, fotodocumentadas, radiografadas e submetidas aos procedimentos histotécnicos de rotina para a confecção das lâminas histológicas com o objetivo de avaliar a neoformação óssea do reparo da área cirúrgica.Como resultado, observou-se que não houve reação inflamatória pelos dados macroscópicos e baixa radiopacidade pela análise radiologica. Desse modo, conclui-se parcialmente que os materiais utilizados são biocompatíveis com o tecido ósseo receptor.

Palavras-Chave: Biomateriais, engenharia tecidual, polímeros, regeneração óssea. 


\section{FLUXOGRAMA PARA ATENDIMENTO DE URGÊNCIAS E EMERGÊNCIAS EM CRISES FALCIFORMES NO HOSPITAL UNIVERSITÁRIO DE JUNDIAÍ}

Gabriel Casagrande Feijó ${ }^{1}$, Maria Eduarda Bueno Tabacchi',

Marilia Soares e Silva Arcadipane², Hélio Alvimar Lotério ${ }^{3}$.

1. Graduando do curso de Medicina; Faculdade de Medicina de Jundiaí

2. Professora Adjunta da Disciplina de Propedêutica do Departamento de Clínica Médica da Faculdade de Medicina de Jundiaí (FMJ), Jundiaí/SP.

3. Professor Adjunto da Disciplina de Hematologia do Departamento de Clínica Médica da Faculdade de Medicina de Jundiaí (FMJ), Jundiaí/SP.

\section{Endereço para correspondência:}

Gabriel Casagrande Feijó - R. Wately, № 400 - Vila Arens, Jundiaí-SP - CEP 13202-520. Tel.: (11) 95289-4737, e-mail: gcasagrande39@gmail.com.

\section{RESUMO:}

Introdução: A anemia falciforme é uma doença monogênica mais comum no Brasil com grande diversidade de manifestações que demanda um manejo correto para aumento da sobrevida do paciente, por essa relação direta com prognostico do paciente há a importância do manejo correto das emergências e urgências da doença Objetivo: Estudo qualitativo, observacional baseado em casos clínicos. Levantamento de prontuários do HU com CID 10 - D57 (incluindo D57.0, D57.1) a partir de janeiro de 2017 com utilização de um questionário de avaliação. Materiais e Métodos: Estabelecer um fluxograma de atendimento para os principais sintomas das crises falcêmicas que se adeque à realidade do Hospital Universitário de Jundiaí. Analisas as causas mais prevalentes de busca a emergência do Hospital Universitário de Jundiaí (HU - FMJ) por pacientes com Anemia Falciforme. Avaliar a relação entre o acompanhamento médico regular da doença em nível ambulatorial e assiduidade no tratamento e a quantidade de internações, a qualidade e expectativa de vida do paciente. Resultados: Analise de 37 prontuários onde os Motivos de internação: Crise álgica - 51,3\%; Febre persistente - 16,2\%; Síndrome torácica aguda - 5,4\%. O Acompanhamento ambulatorial - 60\% e o Uso regular de medicação - $17 \%$. Dos prontuários avaliados apenas dois foram reincidentes. Das Condutas medicas, para os pacientes com queixa de dor a primeira droga de escolha foi dipirona, em $41 \%$ associou-se tramadol e em $29,4 \%$ dos casos, morfina. Em 2 prontuários houve registro de dor refrataria onde a primeira escolha foi a morfina e em 3 prontuário não houve especificação da medicação utilizada. Foi conduta nas crises algicas em 23,55 o uso de oxigenoterapia e reposição volêmica. Nas crises de febre onde se suspeitava de infecção a droga de escolha foi o Ceftriaxone. Óleo mineral em 17,6\% e hemotranfusão em 5,4\% também aparecem. Conclusão: As principais queixas relatadas pelos pacientes condizem com as de maior frequência encontradas na literatura: crise álgica, febre, síndrome torácica aguda. O tratamento adotado no Hospital Universitário nos episódios de crise estão, de modo geral, de acordo com o determinado pelo Ministério da Saúde, excetuando-se na escolha primária do antibiótico em casos de suspeita de infecção: o protocolo criado em 2009 pelo Ministério da Saúde prevê o uso de ampicilina venosa enquanto o mais usado nos prontuários do HU-FMJ foi o ceftriaxone. Não encontramos especificações nas condutas para aumento da ingesta hídrica como recomendado no protocolo. Houve dificuldade na obtenção de dados dos prontuários. $60 \%$ dos pacientes fazem acompanhamento mas há pouca informação sobre esse acompanhamento nos prontuários. Adotando como base o as determinações do Manual de eventos agudos em doença falciforme, redigido pelo Ministério da Saúde em 2009, e adequando ao manejo usual do HU-FMJ, foram montados os fluxogramas anexados no item 9.

Palavras-Chave: anemia falciforme, crises, atendimento, emergências. 


\title{
HISTÓRIAS DE VIDA E DESENVOLVIMENTO DE ENDOMETRIOSE
}

\author{
Fernanda Tarpinian ${ }^{1}$, Camila Gonçalo Mialhe²
}

1. Graduanda do curso de Medicina; Faculdade de Medicina de Jundiaí

2. Professora Adjunta das disciplinas de Políticas Públicas de Saúde/ Atenção Primária e Educação em Saúde do Departamento de Saúde Coletiva da Faculdade de Medicina de Jundiaí (FMJ), Jundiaí/SP.

\section{Endereço para correspondência:}

Fernanda Tarpinian - R. Zuferey, no 241 - Vila Arens, Jundiaí-SP - CEP 13202-420. Tel.: (11) 971177650, e-mail: tarpinian.fernanda@gmail.com

\section{RESUMO:}

Introdução: A endometriose é uma doença crônica que vem sendo considerada um problema de saúde pública entre as brasileiras. A literatura científica sugere que experiências de vida que imprimiram forte carga emocional nessas mulheres podem contribuir com a gênese e o desenvolvimento da condição de saúde supracitada. Objetivo: Verificar se, na visão das participantes, eventos que ocorreram em suas vidas influenciaram no desenvolvimento da endometriose severa (grau IV), e se essas mulheres utilizam PICs (Práticas Integrativas e Complementares) para aliviar/tratar os sintomas gerados por esta doença. Materiais e Métodos: Trata-se de um estudo exploratório quanti-qualitativo, cuja coleta de dados se deu por meio de questionário eletrônico. No mês de Março/2020 foi feito o pré teste para o ajuste das perguntas e a coleta dos dados. Os achados quantitativos foram submetidos à análise estatística descritiva e o conteúdo dos dados qualitativos foi analisado tematicamente. Resultados: Os 83 questionários respondidos online revelaram que a maioria das participantes apresentou faixa etária entre 31 e 40 anos $(n=43 ; 51,8 \%)$, casadas ( $n=56 ; 67,5 \%)$, com grau de escolaridade superior completo $(n=45 ; 54,2 \%)$, e diagnóstico de endometriose severa (grau IV) há 1 e 2 anos $(n=27 ; 32,5 \%)$. A análise temática revelou que a endometriose interfere na qualidade de vida dessas mulheres à medida que gera sofrimento de várias ordens, principalmente na parte física, emocional e na área dos relacionamentos. Os dados quantitativos demonstram que eventos que ocorreram na vida das respondentes foram relacionados com o desenvolvimento da endometriose por 29 participantes (29\%). Entretanto, a conexão entre eventos vivenciados e a melhora/piora da endometriose foi mencionada por 43 mulheres (52\%). As PICs são utilizadas para auxiliar nos desconfortos causados pela endometriose em 18\% ( $n=15)$ das respondentes, enquanto a Ginecologia Natural tem sido empregada por $61 \%(n=51)$ delas. Conclusão: Conclui-se que, no universo pesquisado, a maioria das mulheres revelou desconexão entre eventos vivenciados e a gênese da endometriose, bem como apontou conexão entre a melhora/piora dos sintomas da doença com fatos vividos. Referente aos métodos não alopáticos para o tratamento ou alívio dos sintomas da endometriose, o uso da Ginecologia Natural se sobressaiu ao uso de PICs.

Palavras-Chave: Educação de Graduação em Medicina; Endometriose; Ginecologia; Ginecologia Natural; Medicina Integrativa 


\title{
HUMANIZAÇÃO DE UM AMBULATÓRIO MÉDICO DA CIDADE DE JUNDIAÍ: LEVANTAMENTO DOS INDICADORES DE AVALIAÇÃO EM SAÚDE
}

\author{
Bruna Ozaki de Almeida1', Gabriel Talioli Rabelo de Lima¹, Ana Cláudia Giesbrecht Puggina²
}

1. Graduando do curso de Medicina; Faculdade de Medicina de Jundiaí (FMJ), Jundiaí/SP.

2. Professora adjunta da Disciplina de Pesquisa em Saúde do Departamento de Saúde Coletiva da Faculdade de Medicina de Jundiaí (FMJ), Jundiaí/SP.

\section{Endereço para correspondência:}

Bruna Ozaki de Almeida - R. Itaprias, № 50, apto 161 - Vila Mariana, São Paulo-SP - CEP 04118-100 Tel.: (11) 95725-5500 E-mail: bruozaki@gmail.com

\section{RESUMO:}

Introdução: A Política Nacional de Humanização (PNH) é fundamental na assistência à saúde e a partir de seus pilares - autonomia, transversalidade e cogestão - guia a construção de diretrizes e dispositivos que corroboram para o processo de humanização em saúde. Objetivo: (1) identificar os indicadores de avaliação em saúde de um ambulatório médico de especialidades; (2) associar as variáveis socioeconômicas com os fatores do Índice de Humanização dos Serviços (IHS) na dimensão usuário. Materiais e Métodos: Estudo transversal quantitativo. A amostra foi constituída por usuários, profissionais em saúde e gestores de um ambulatório médico de especialidades. Foi utilizado o instrumento psicométrico validado IHS composto por 15 fatores divididos em 3 dimensões - usuário, profissional e gestor. A coleta de dados foi realizada por meio de entrevista via formulário eletrônico. Foram realizadas análise descritiva e comparativa através de testes estatísticos. A probabilidade de erro adotada foi de $p<0,05$. Resultados: participaram do estudo 171 usuários, 19 profissionais e 3 gestores. O Índice Geral da Dimensão Usuário foi classificado "muito bom" $(0,81)$, da Dimensão Profissional como "bom" $(0,72)$ e da Dimensão Gestor como "muito ruim" $(0,38)$. O IHS foi categorizado como "bom" $(0,64)$. Os fatores com as piores classificações em cada dimensão representam aqueles que precisam ser urgentemente melhorados no serviço tais como visibilidade e adequação da $\mathrm{PNH}$ no ambulatório; impacto das diretrizes da PNH na gestão; e conhecimento da área adstrita do ambulatório e rede de atenção do município. A excelência do serviço apresentou-se nos fatores mais bem avaliados em cada dimensão tais como resolutividade, acolhimento, respeito ao sigilo, confidencialidade, ambiente adequado, apoio da gestão e gestão participativa. Na dimensão usuário, encontrou-se associações estatisticamente significativas nas comparações entre o item que mostra que a instituição disponibiliza dispositivos de humanização com as variáveis escolaridade $(p=0,015)$ e conhecimento ou não da $\mathrm{PNH}(p=0,004)$. Outra comparação significativa foi entre 0 item que indica se unidade desenvolve atividades lúdicas $e$ de lazer voltados aos usuários com o conhecer ou não a PNH $(p=0,003)$ e a cor autorreferida $(p=0,032)$. Conclusão: $O \mathrm{IHS}$ foi considerado bom e adequado de acordo com a $\mathrm{PNH}$, contudo foram encontrados déficits na visibilidade e impacto da política em todas as dimensões. Desconhecer a $\mathrm{PNH}$, autorreferir-se "preto ou pardo" e baixa escolaridade foram fatores que interferiram negativamente na visibilidade da aplicação da PNH e na percepção das atividades lúdicas desenvolvidas no serviço.

Palavras-Chave: Políticas Públicas de Saúde, Humanização da Assistência, Indicadores de Serviços, Avaliação em Saúde, Relações Médico-Paciente. 


\title{
INVESTIGAÇÃO DE ENTEROPARASITOSES EM CRIANÇAS ATENDIDAS NA UNIDADE DE SAÚDE DA FAMÍLIA VILA ANA, JUNDIAÍ-SP, NO PERÍODO DE 2019
}

\author{
Heráclito Andrade Vicente ${ }^{1}$, Laís Santos Araújoํㅜ, Ana Paula Antunes Pascalicchio Bertozzi²,
} Alcione Vendramin Gatti ${ }^{3}$.

1. Graduando do curso de Medicina; Faculdade de Medicina de Jundiaí (FMJ), Jundiaí/SP.

2. Professora Auxiliar de Pediatria e Vice-Coordenadora do Departamento de Pediatria da Faculdade de Medicina de Jundiaí (FMJ), Jundiaí/SP.

3. Professora Adjunta da Disciplina de Parasitologia da Faculdade de Medicina de Jundiaí (FMJ), Jundiaí/SP.

\section{Endereço para correspondência:}

Heráclito Andrade Vicente - Rua Zuferey no 241, Bloco 05, Apartamento 401 - Vila Arens, Jundiaí-SP - CEP 13202-420 Tel.: (35) 988917535, e-mail: heraclitoav@gmail.com

\section{RESUMO:}

Introdução: As enteroparasitoses representam as doenças mais comuns da população mundial. Podem causar prejuízo no equilíbrio nutricional do hospedeiro, reduzir a absorção de nutrientes e a ingestão alimentar, e induzir o sangramento intestinal. Em complicações nos casos de superpopulação de parasitas podem até levar o hospedeiro ao óbito. O presente estudo pretende auxiliar na elucidação do panorama de infecções por enteroparasitas de uma parcela da população de crianças jundiaienses, através da análise de dados obtidos por exames de fezes realizados na Unidade de Saúde da Família Vila Ana, em Jundiaí, e com isso colaborar com propostas de ações de promoção de saúde direcionadas nesta Unidade. Objetivo: Quantificar as ocorrências de enteroparasitoses, identificar o perfil e as causas destas parasitoses nos indivíduos atendidos na USF, e comparar os resultados desta pesquisa com uma realizada em 2014/2015. Materiais e Métodos: Foi realizada análise de prontuários e exames coproparasitológicos que já constavam no banco de dados desta USF (referentes ao primeiro semestre de 2019), e dos exames solicitados ao longo do segundo semestre do estudo e primeiros meses de 2020. As variáveis analisadas foram sistematizadas em planilha Excel. Resultados: Foram estudados 45 prontuários dos pacientes. $O$ agente etiológico mais presente o Endolimax nana. Discussão: Foi encontrada dificuldade na solicitação e coleta de exames de fezes, causando escassez de resultados a serem analisados. A maior dificuldade diz respeito a não realização de exames durante o período de pandemia do COVID-19. Porém, é importante pontuar que antes da pandemia o volume de pedidos de tais exames já era baixo, indicando possível desinteresse por parte dos profissionais de saúde no estudo das parasitoses, ou a crença de que pacientes assintomáticos não necessitam da investigação da doença através do exame. Conclusão: As enteroparasitoses ainda estão presentes nesta população jundiaiense. Apesar de se tratar de uma porcentagem baixa de infectados $(11,11 \%)$, esse perfil epidemiológico é um importante indicativo de uma possível falta de conhecimento sobre o processo saúde doença vivenciado. Com a dificuldade na coleta de dados para o estudo foi difícil compreender se o padrão de infecção se alterou ao longo dos anos na região. Entretanto, a presença de casos positivos evidencia pontos que podem necessitar de cuidados dentro das condições sanitárias. Para melhorar este quadro, pode-se propor projetos educativos e informativos, levando instrução à população na USF, nas creches, escolas e demais ambientes. Dessa forma, o presente estudo corrobora para a percepção de que é importante conduzir e manter as medidas de educação da população e disseminar informações de prevenção, a fim de proteger e garantir o desenvolvimento do grupo populacional infantil.

Palavras-Chave: Enteroparasitose, intestino, higiene, doença, saúde, parasitas, crianças. 


\section{LITERACIA EM SAÚDE EM ADULTOS DIABÉTICOS USUÁRIOS DO SERVIÇO PÚBLICO DE SAÚDE EM MUNICÍPIOS DE SÃO PAULO}

Victoria Pedrazzoli Rodrigues ${ }^{1}$, Laura Ribeiro de Matos ${ }^{1}$, Carla Fabiana Tenani², Marilia Jesus Batista ${ }^{3}$

1. Graduanda do curso de Medicina; Faculdade de Medicina de Jundiaí (FMJ), Jundiaí/SP.

2. Professora Coorientadora. Doutoranda do Departamento de Ciências em Saúde e Odontologia Infantil da Faculdade de Odontologia de Piracicaba da Universidade Estadual de Campinas, FOPUNICAMP, Piracicaba/SP.

3. Orientadora. Professora da Disciplina de Epidemiologia do Departamento de Saúde Coletiva, Faculdade de Medicina de Jundiaí (FMJ), Jundiaí/SP.

\section{Endereço para correspondência:}

Victoria Pedrazzoli Rodrigues - R. Francisco Teles, 250 - Vila Arens II, Jundiaí - SP, CEP: 13202-550, Tel.: (11) 3395-2100, e-mail: victoriapedrazzoli@hotmail.com

\section{RESUMO:}

Introdução: o aumento na prevalência de diabetes tipo 2, relatado nas três últimas décadas, apresenta-se como um problema de saúde global e que merece especial atenção para a elaboração de ações de promoção de saúde. A literacia em saúde (LS), que possibilita o aumento do controle dos indivíduos sobre a sua saúde, torna-se uma importante estratégia para promover melhorias no autocuidado e controle dos fatores de risco da doença. Objetivo: o estudo avaliou LS em adultos diabéticos, usuários do serviço público de saúde em dois municípios, e verificou a associação com fatores socioeconômicos, demográficos e de comportamentos em saúde. Materiais e Métodos: foi realizado um estudo transversal, com adultos e idosos portadores de diabetes, em duas unidades de saúde, uma em Jundiaí e outra em Piracicaba, São Paulo. Foram avaliados: fatores socioeconômicos, comportamentos em saúde, condições clínicas, uso de serviço de saúde e nível de LS. Os valores de glicemia e hemoglobina glicada foram consultados nos prontuários de cada usuário. A LS foi a variável explanatória, e as variáveis dependentes foram os índices clínicos: glicêmico e hemoglobina glicada (Hb1Ac). Resultados: a maioria dos participantes foi do sexo feminino, sendo que 67,6\% ( $n=48$ ) possuíam glicemia alterada (acima de $127 \mathrm{mg} / \mathrm{dl}$ ) e 59,1\% ( $n=39$ ) tinham $\mathrm{Hb} 1 \mathrm{Ac}$ acima de $8 \%$. A média de LS encontrada foi de 41,5 e $51,6 \% \quad(n=46)$ apresentam baixa LS. O estudo mostrou que a LS foi relacionada principalmente a moradia, glicemia em jejum, escolaridade, tabagismo e raça $(p<0,05)$. A alta LS foi mais prevalente em indivíduos que não eram fumantes, com maior grau de escolaridade e não brancos. Conclusão: os dados do presente estudo mostram associação da literacia com variáveis clínicas e comportamentos em saúde, indicando que a LS deve ser considerada nas estratégias de promoção de saúde. Futuros estudos devem buscar esclarecer o papel da LS associado às diabetes e comportamentos em saúde.

Palavras-chave: Doença Crônica; Alfabetização em Saúde; Diabetes Mellitus; Adulto. 


\section{METODOS CONTRACEPTIVOS REVERSÍVEIS DE LONGA DURAÇÃO EM MULHERES ADOLESCENTES: SATISFAÇÃO NO USO, PADRÃO MENSTRUAL E MODIFICAÇÕES NA FLORA VAGINAL}

Viviane de Souza Gomes ${ }^{1}$; Ana Paula Ghussn Cano²; Rose Luce Gomes do Amaral ${ }^{3}$

1. Graduanda do curso de Medicina; Faculdade de Medicina de Jundiaí

2. Residente da especialidade de Ginecologia e Obstetrícia; CAISM- Unicamp

3. Professora Adjunta da Disciplina de Ginecologia do Departamento de Tocoginecologia da Faculdade de Medicina de Jundiaí (FMJ), Jundiaí/SP.

\section{Endereço para correspondência:}

Viviane de Souza Gomes - R Zuferey, oㅜ 155- Bloco 5 ap 104 - Vila Arens, Jundiaí-SP - CEP 13202420. Tel.: (19) 99386-2554, e-mail: vivianegomez1@hotmail.com.

\section{RESUMO:}

Introdução: Mulheres adolescentes compõe o grupo etário de maior associação com ocorrência de gestações indesejadas e apresentam complicações importantes relacionadas ao parto e puerpério. $O$ uso de anticoncepcionais seguros e efetivos é essencial para a prevenção de gestações indesejadas e suas complicações. Diante disso, métodos contraceptivos de longa duração (LARCs) são métodos práticos e de primeira escolha para esse fim, entre os diversos tipos, os dispositivos intrauterinos hormonais vem se destacando. $O$ uso desse método pode causar alterações no sangramento menstrual e também nas características do ecossistema vaginal residente. Objetivos: Conhecer o perfil epidemiológico das mulheres adolescentes que se interessam pelos LARCs, fornecer os dispositivos, avaliar o grau de satisfação das mesmas com seu uso, as mudanças no padrão menstrual, bem como as alterações na flora vaginal após a utilização dos dispositivos. Materiais e Métodos: Foram incluidas 26 participantes, para as quais foi aplicado questionário, orientadas quanto o preenchimento do diário menstrual e realizado exame ginecológico, durante o exame foi realizada coleta de material vaginal para exame de bacterioscopia com coloração de gram, bacterioscopia a fresco e microbioma. $O$ material coletado foi armazenado corretamente em refrigerador para ser analisado. Resultados: Dentre as participantes, $34,6 \%$ já estavam previamente em acompanhamento no ambulatório e $65,4 \%$ foram encaminhadas do nível primário de atenção à saúde para avaliação de anticoncepção. Antecedente de uma gestação prévia foi descrito por $23,1 \%$ das participantes. Uso de método contraceptivo nos últimos 6 meses foi descrito por $88,4 \%$ das adolescentes. Apenas uma paciente referiu fazer uso de condom associado ao uso de outro método contraceptivo. O diagnóstico de vaginose bacteriana através dos critérios de Nugent foi confirmado em 6 pacientes (23,1\%). Não houve relação entre o número de parceiros na vida e o diagnóstico de vaginose bacteriana pelos critérios de Nugent $(p=0,518)$. Uma participante referiu antecedente de sífilis tratada e uma apresentava, ao exame físico, condilomatose vulvar e vaginal. Devido à interrupção do atendimento e de todas as pesquisas que não estão relacionadas ao Covid-19 dentro do Hospital CAISM da Unicamp, a maioria dos casos ficaram sem completar a avaliação de tal maneira que nem todos os objetivos puderam ser alcançados. Conclusão: A maior parte das adolescentes estava em uso de métodos associados a altas taxas de gestações indesejadas. O estímulo e fornecimento de métodos contraceptivos de alta eficácia, associado ao aconselhamento contraceptivo é essencial para motivar as adolescentes a aderirem a um método contraceptivo seguro já desde o início de sua vida sexual, antes da ocorrência de desfechos indesejados. Apesar de haver um serviço em hospital terciário voltado para a adolescente, a maioria foi oriunda de unidade básica de saúde, corroborando a importância em descentralizar o atendimento em planejamento familiar da mulher adolescente.

Palavras-Chave: Métodos Contraceptivos de longa duração (LARCs), mulheres adolescentes. 


\title{
O PAPEL DA VIA DE SINALIZAÇÃO DA FOSFATIDILINOSITOL-3-QUINASE (PI3K) NOS EFEITOS INIBITÓRIOS DAS ENTEROTOXINAS ESTAFILOCÓCICAS DO TIPO A (SEA) E B (SEB) SOBRE AS PROPRIEDADES FUNCIONAIS DE NEUTRÓFILOS
}

\author{
Gustavo Dias Teixeira ${ }^{1}$, Ana Luisa Marossi Justiniano ${ }^{1}$, Henrique Herrera Piguin ${ }^{1}$, \\ Ana Paula Ferreira Duarte²; Ivani Aparecida de Souza ${ }^{3}$.
}

1. Graduando do curso de Medicina; Faculdade de Medicina de Jundiaí

2. Doutoranda da Pós-graduação em Ciências da Saúde da Faculdade de Medicina de Jundiaí (FMJ), Jundiaí/SP.

3. Professor Adjunto da Disciplina de Fisiologia Humana do Departamento de Biologia e Fisiologia, Faculdade de Medicina de Jundiaí (FMJ), Jundiaí/SP.

\section{Endereço para correspondência:}

Nome do Autor: Gustavo Dias Teixeira - R. Zuferey, no 211 (bl. 6, apto 302) - Vila Arens, Jundiaí-SP CEP 13202-420. Tel.: (11) 98272-2900, e-mail: gdias1993@hotmail.com

\section{RESUMO:}

Introdução: A sepse é uma doença inflamatória sistêmica que atinge cerca de 17 milhões de pessoas por ano em todo o mundo. É a principal causa de admissão e morte de pacientes nas unidades de terapia intensiva. A sepse por bactérias gram-positivas apresenta maior índice de mortalidade do que a sepse por bactérias gram-negativas. Uma inadequada mobilização de neutrófilos em quadros de sepse grave por Staphylococcus aureus é a principal causa de morte em pacientes infectados por esta bactéria. Os efeitos patológicos do Staphylococcus aureus se devem à produção e a secreção das enterotoxinas estafilocócicas (SEs). Recentemente, demonstramos que granulócitos do sangue humano incubados com SEs apresentam redução nas propriedades funcionais de quimiotaxia e adesão via ativação do $\mathrm{MHC}$ classe II. Objetivo: $O$ presente estudo visa identificar o papel da via de sinalização da PI3K na disfunção de neutrófilos produzida pelas SEs do tipo A (SEA) e B (SEB). Materiais e Métodos: Amostras $(40 \mathrm{ml})$ de sangue foram coletadas de voluntários saudáveis após aprovação do comitê de ética em pesquisa da FMJ (Protocolo № 61370616.3.0000.5412). As amostras de sangue foram colocadas em solução isotônica de Percoll e após centrifugação, eritrócitos e granulócitos foram aspirados e submetidos a lise isotônica. A seguir as células (98\% neutrófilos), ressuspensas na concentração de $4 \times 10^{6}$ células $/ \mathrm{ml}$, foram submetidas a incubação in vitro com SEA ou SEB $(100 \mathrm{ng} / \mathrm{ml}$; $2 \mathrm{~h}$ ). Os ensaios de adesão foram realizados em placas previamente revestidas com as moléculas de adesão VCAM-1 e ICAM-1 e os ensaios de quimiotaxia foram realizados em câmara de Boyden, ambos na presença de interleucina-8 (IL-8). Em alguns protocolos experimentais os neutrófilos foram incubados com o Wortmanin (um inibidor específico da PI3K; $10 \mathrm{mM}$ ), antes da incubação com as SEs Resultados: O tratamento prévio de neutrófilos com um inibidor específico da PI3K restaura a capacidade de adesão e quimiotaxia destas células. Incluímos também como objetivo analisar a expressão proteica da PI3K em neutrófilos por Western Blooting. No entanto, devido as medidas de isolamento social em função da pandemia do COVID-19 estas etapas foram interrompidas. Conclusão: A incubação de neutrófilos do sangue humano com SEA ou SEB resulta em redução das propriedades funcionais de quimiotaxia e adesão destas células. Este efeito é revertido com a inibição da PI3K em neutrófilos o que ressalta o envolvimento desta via nas ações das SEs nestas células.

Palavras-Chave: Neutrófilos, Sepse, Enterotoxinas estafilocócicas. 


\section{O PAPEL DA VIA DE SINALIZAÇÃO DA p38 MAPK NA DISFUNÇÃO DE NEUTRÓFILOS PRODUZIDA PELAS ENTEROTOXINAS ESTAFILOCÓCICAS DO TIPO A (SEA) E B (SEB)}

Ana Luisa Marossi Justiniano', Gustavo Dias Teixeira ${ }^{1}$, Henrique Herrera Piguin ${ }^{1}$, Ana Paula Ferreira-Duarte²; Ivani Aparecida de Souza ${ }^{3}$.

1. Graduando do curso de Medicina; Faculdade de Medicina de Jundiaí

2. Doutoranda da Pós graduação em Ciências da Saúde da Faculdade de Medicina de Jundiaí (FMJ), Jundiaí/SP.

3. Professor Adjunto da Disciplina de Fisiologia Humana do Departamento de Biologia e Fisiologia, Faculdade de Medicina de Jundiaí (FMJ), Jundiaí/SP.

\section{Endereço para correspondência:}

Nome do Autor: Ana Luisa Marossi Justiniano - R. das Pitangueiras, oㅜ 22, apto 11 - Jardim Pitangueira, Jundiaí-SP - CEP13.202.450. Tel.: (17) 98164-9298, e-mail: analuisa_mj@hotmail.com

\section{RESUMO:}

Introdução: A sepse é uma doença inflamatória sistêmica que atinge cerca de 17 milhões de pessoas por ano em todo o mundo. É a principal causa de admissão e morte de pacientes nas unidades de terapia intensiva. A sepse por bactérias gram-positivas apresenta maior índice de mortalidade do que a sepse por bactérias gram-negativas. Uma inadequada mobilização de neutrófilos em quadros de sepse grave por Staphylococcus aureus é a principal causa de morte em pacientes infectados por esta bactéria. Os efeitos patológicos do Staphylococcus aureus se devem à produção e a secreção das enterotoxinas estafilocócicas (SEs). Recentemente, demonstramos que granulócitos do sangue humano incubados com SEs apresentam redução nas propriedades funcionais de quimiotaxia e adesão via ativação do $\mathrm{MHC}$ classe II. Objetivo: $O$ presente estudo visa identificar o papel da via de sinalização da p38 MAPK na disfunção de neutrófilos produzida pelas SEs do tipo A (SEA) e B (SEB). Materiais e Métodos: Amostras $(40 \mathrm{ml})$ de sangue foram coletadas de voluntários saudáveis após aprovação do comitê de ética em pesquisa da FMJ (Protocol No 61370616.3.0000.5412). As amostras de sangue foram colocadas em solução isotônica de Percoll e após centrifugação eritrócitos e granulócitos foram aspirados e submetidos à lise isotônica. A seguir as células (98\% neutrófilos), ressuspensas na concentração de $4 \times 10^{6}$ células $/ \mathrm{ml}$, foram submetidas a incubação in vitro com SEA ou SEB $(100 \mathrm{ng} / \mathrm{ml}$; $2 \mathrm{~h}$ ). Os ensaios de adesão foram realizados em placas previamente revestidas com as moléculas de adesão VCAM-1 e ICAM-1 e os ensaios de quimiotaxia foram realizados em câmara de Boyden, ambos na presença de interleucina-8 (IL-8). Em alguns protocolos experimentais os neutrófilos foram incubados com o SB203580 (um inibidor específico da p38 MAPK; $1 \mu \mathrm{M}$ ), antes da incubação com as SEs Resultados: O tratamento prévio de neutrófilos com um inibidor específico da p38 MAPK restaura a capacidade de adesão e quimiotaxia destas células. Incluímos também como objetivo analisar a expressão proteica da p38 MAPK em neutrófilos por Western Blooting. No entanto, devido as medidas de isolamento social em função da pandemia do COVID-19 estas etapas foram interrompidas. Conclusão: A incubação de neutrófilos do sangue humano com SEA ou SEB resulta em redução das propriedades funcionais de quimiotaxia e adesão destas células. Este efeito é revertido com a inibição da p38 MAPK em neutrófilos o que ressalta o envolvimento desta via nas ações das SEs nestas células.

Palavras-Chave: Neutrófilos, Sepse, Enterotoxinas estafilocócicas. 


\section{PERFIL EPIDEMIOLÓGICO DA POPULAÇÃO ADULTA ATENDIDA PELO PROJETO VOZES DAS RUAS EM JUNDIAÍ}

João Paulo Bartolo de Siqueira1, Lucas Castro Pires², Lucas Gabrício Marçola ${ }^{3}$, Natália Arthur Vieira ${ }^{4}$, Raissa Alves Jorge ${ }^{5}$, Adriano Pires Barbosa ${ }^{6}$, Marília Jesus Batista de Brito Mota ${ }^{7}$

1. Graduando do curso de Medicina; Faculdade de Medicina de Jundiaí.

2. Professor Adriano Pires Barbosa, professor assistente do Departamento de Saúde Coletiva, Faculdade de Medicina de Jundiaí (FMJ), Jundiaí/SP

3. Professora Dra. Marilia Jesus Batista (orientadora), professora da Disciplina de Epidemiologia do Departamento de Saúde Coletiva, Faculdade de Medicina de Jundiaí (FMJ), Jundiaí/SP.

\section{Endereço para correspondência:}

João Paulo Bartolo de Siqueira - Rua José Beraldi, № 225 - Portal do Paraíso 1, Jundiaí-SP - CEP 13214-731. Tel.: (11) 4582-3293, e-mail: joao_p.bartolo@hotmail.com.

\section{RESUMO:}

Introdução: A transição epidemiológica no Brasil é caracterizada pela carga tripla da doença, já que além do aumento das doenças crônicas não transmissíveis (DCNT), ainda há alta incidência das doenças transmissíveis e aumento da mortalidade por causas externas. Objetivo: Assim, o objetivo deste estudo foi avaliar o perfil epidemiológico da população acima de 18 anos atendida pelo Projeto Vozes das Ruas (PVR), em Jundiaí, São Paulo. Materiais e Métodos: Foi elaborado um estudo quantitativo transversal com a população atendida durante mutirões de saúde, realizados pelo PVR, sendo aplicado um questionário para coleta de dados sociodemográficos e comportamento em saúde, realizando também a medida da glicemia capilar, mensuração da Pressão Arterial, peso, altura e circunferência abdominal. Além disso, foi feita a análise descritiva dos dados e verificada a associação das DCNT (diabetes e hipertensão) com as variáveis independentes do estudo através do teste Quiquadrado ou do Teste Exato de Fisher, sendo realizada a regressão logística univariada e regressão logística multivariada para as variáveis com $p<0,20$. O intervalo de confiança adotado foi de $95 \%$. Resultados: A amostra do estudo foi de 580 pessoas, $50 \%$ sexo masculino, $50 \%$ sexo feminino e uma idade média de 48,56 anos. Mais de 40\% da amostra não apresentou ensino médio completo e 37,6\% das famílias apresentou uma renda mensal de até dois salários mínimos Houve, ainda, uma grande prevalência de indivíduos não praticantes de exercícios físicos, que consomem alimentos ultraprocessados e que apresentam sobrepeso ou obesidade. Foi observada uma prevalência autodeclarada de $23,2 \%$ de Diabetes (DM) e de 43,2\% de Hipertensão Arterial Sistêmica (HAS). Conclusão: Pela análise multivariada, os fatores de risco para DM foram: idade acima de 39 anos, antecedente familiar de DM, uso de UBS, histórico de tabagismo, antecedente pessoal de HAS e como fator de proteção: negar uso de medicações de uso contínuo. Em relação à HAS, os fatores de risco pela multivariada foram: faixa etária acima de 39 anos, menos de oito anos de estudo, antecedente pessoal de DM, sobrepeso e obesidade, já os fatores de proteção foram: tabagismo e negar uso de medicações de uso contínuo. Os dados obtidos pelo presente estudo permitiram conhecer o perfil epidemiológico da população de Jundiaí atendida pelo PVR e os fatores associados às DCNT mais prevalentes, possibilitando a obtenção de subsídios para estratégias de prevenção e promoção de saúde.

Palavras-Chave: Adulto, doenças crônicas, epidemiologia. 


\section{PERFIL EPIDEMIOLÓGICO DE CÂNCER GINECOLÓGICO NO SISTEMA ÚNICO DE SAÚDE DE JUNDIAÍ}

Camila Abacherli Morales Castro ${ }^{1}$, Marcela Ercolini Carnio', Ana Carolina Marchesini de Camargo², Marcello Ferretti Fanelli ${ }^{3}$

1. Graduando do curso de Medicina; Faculdade de Medicina de Jundiaí

2. Professora Adjunta da Disciplina de Ginecologia do Departamento de Tocoginecologia da Faculdade de Medicina de Jundiaí (FMJ), Jundiaí/SP.

3. Professor Adjunto da Disciplina de Oncologia Clínica do Departamento de Clínica Médica, Faculdade de Medicina de Jundiaí (FMJ), Jundiaí/SP.

\section{Endereço para correspondência:}

Camila Abacherli Morales Castro - R. Zuferey, № 183, Complemento Bloco 03, apartamento 302 - Vila Arens, Jundiaí-SP - CEP 13202-420. Tel.: (11) 97224-9599, e-mail: camila.a.m.castro96@gmail.com.

\section{RESUMO:}

Introdução: O câncer ginecológico é uma importante questão de saúde pública devido à sua alta prevalência e mortalidade. A detecção precoce é fundamental para garantir o sucesso do tratamento e a sobrevida da paciente, sendo que o limite determinado por Lei Federal é de 60 dias a partir da data do diagnóstico. Trata-se de uma doença multifatorial, com várias características que podem alterar sua evolução e sobrevida dos pacientes, por isso a importância de se estudar profundamente variáveis que podem alterar sua história natural. Objetivo: O objetivo geral é estabelecer a incidência das neoplasias ginecológicas e possíveis associações com fatores específicos na população da cidade de Jundiaí. Materiais e Métodos: Trata-se de um estudo retrospectivo do tipo corte transversal a ser realizado no Instituto de Oncologia de Jundiaí, com análise de prontuários no período de 2009 a 2019. Resultados: O câncer de colo do útero foi o mais prevalente, correspondendo $47,3 \%$ dos casos, seguido pelo câncer de ovário $(30 \%)$, de endométrio (19\%), de vulva (3\%) e de vagina (1\%). Na neoplasia endometrial, notou-se uma maior relação com comorbidades e sobrepeso, sendo que $77,1 \%$ das pacientes apresentavam pelo menos uma patologia prévia, também predominando HAS e DM, e o IMC foi $>25$ em $68,1 \%$. Quanto ao tempo decorrido entre o diagnóstico definitivo pelo exame anatomopatológico até início do tratamento e entre a data da consulta com oncologista. Em $55,5 \%$ dos casos as pacientes conseguiram iniciar a primeira linha de tratamento respeitando a lei dos 60 dias proposta pelo SUS a partir de 2012. Quando comparamos o tempo entre o diagnóstico e o início do tratamento antes e depois da implementação da "Lei dos 60 dias", observamos um aumento de acesso ao tratamento de 0 a 2 meses, além de uma queda de 2 a 6 meses e de 6 a 12 meses. Conclusão: A maioria acomete pacientes acima de 45 anos (81,3\%). O câncer de colo uterino ainda é o mais prevalente e tem o maior atraso para o início de tratamento, apesar do programa de rastreamento. Na nossa casuística o câncer de ovário é mais prevalente que o câncer de endométrio, e é o câncer com menor tempo de espera para instituição da primeira linha de tratamento. Após a introdução da lei dos 60 dias pelo Ministério da Saúde, houve redução do tempo decorrido entre o diagnóstico e a instituição da primeira linha de tratamento para os cânceres estudados.

Palavras-Chave: câncer ginecológico em Jundiaí, perfil epidemiológico do câncer ginecológico, diagnóstico precoce, fatores prognósticos do câncer. 


\section{PIC: DISTRIBUIÇÃO TERRITORIAL E DEMANDA NAS UNIDADES DE SAÚDE DE JUNDIAÍ}

Jaqueline Midori Tominaga Gouveia ${ }^{1}$, Camila Gonçalo Mialhe²

1. Graduanda do curso de Medicina; Faculdade de Medicina de Jundiaí

2. Professora Adjunta das disciplinas de Políticas Públicas de Saúde/ Atenção Primária e Educação em Saúde do Departamento de Saúde Coletiva da Faculdade de Medicina de Jundiaí (FMJ), Jundiaí/SP.

\section{Endereço para correspondência:}

Jaqueline Midori Tominaga Gouveia - R. Visconde de Taunay, o 206 apto 1002 - Vila Arens, JundiaíSP - CEP 13202540 Tel.: (11) 992425627, e-mail: jaquegouveia1510@outlook.com

\section{RESUMO:}

Introdução: Conhecer a distribuição territorial e a demanda por serviços de saúde na rede pública é importante, pois, são aspectos contemplados nos princípios que regem o Sistema Único de Saúde (SUS). Tais princípios, descritos na Lei no. 8080 de 19 de setembro de 1990, também preconizam a divulgação de informações sobre o potencial dos serviços de saúde e a sua utilização pelo usuário, bem como determinam a participação da comunidade nas ações e serviços oferecidos pelos SUS. Objetivo: Verificar a distribuição territorial e a demanda dos serviços de Práticas Integrativas e Complementares (PIC) oferecidos em unidades de saúde no município de Jundiaí-SP. Materiais e Métodos: Trata-se de um estudo quanti-qualitativo exploratório, conduzido em duas fases. A primeira fase foi realizada por meio de contato telefônico, contato pessoal e pesquisa documental, para fazer o levantamento inicial das unidades de saúde que implantaram PIC. A segunda fase da pesquisa foi composta de aplicação de questionário online para profissionais que atuam em tais unidades. Os dados provenientes destes questionários foram analisados por meio de estatística descritiva e de análise de conteúdo temática. Resultados: Dentre as 35 unidades de saúde no município de Jundiaí, 20 (57\%) implantaram as PIC, sendo as mais oferecidas: Auriculoterapia ( $n=05 ; 23 \%)$, Lian Gong ( $n=4 ; 18 \%)$ e Dança Circular $(n=4 ; 18 \%)$. A maioria das PIC tem sido disponibilizada duas vezes na semana $(n=18$; $50 \%$ ), principalmente no período da manhã ( $n=26 ; 72 \%$ ) e para o público em geral ( $n=05 ; 55 \%)$. O Lian Gong foi a modalidade de PIC que apresentou maior número de capacitações entre os participantes ( $n=8 ; 28,6 \%$ ) e os atendimentos/atividades por meio das PIC têm sido oferecidos mais na lógica de cuidado complementar em saúde $(n=10 ; 91 \%)$ do que lógica biomédica $(n=01 ; 9 \%)$. A análise temática dos dados revelou que os respondentes acreditam que as PIC são uma demanda na unidade de saúde, pois, os usuários procuram pelos atendimentos e os profissionais sentem necessidade de atuar por meio de abordagens de cuidado mais abrangentes, além de constatarem melhorias e benefícios na vida dos usuários atendidos. Conclusão: A distribuição das PIC vem acontecendo na maior parte das unidades de saúde no SUS-Jundiaí, e, na visão dos respondentes, existe demanda para o uso das PIC no cenário estudado. Sugere-se a condução de um novo estudo para conhecer a visão dos usuários sobre a oferta de PIC no âmbito pesquisado, complementando assim, os achados supracitados.

Palavras-Chave: Atenção Primária à Saúde; Sistema Único de Saúde; Terapias Complementares. 


\section{PREFERÊNCIAS dOS PAIS NA PARTICIPAÇÃO DA ANESTESIA DE SEUS FILHOS}

Jéssica Mayara Mesquita Ivanovs ${ }^{1}$, Marina Araújo Dias ${ }^{1}$,

Patrícia Millás Ribeiro², José Fernando Amaral Meletti ${ }^{3}$.

1. Graduando do curso de Medicina; Faculdade de Medicina de Jundiaí (FMJ).

2. Médica em Especialização em Anestesiologia-SBA da Faculdade de Medicina de Jundiaí (FMJ).

3. Professor Titular da Disciplina de Anestesiologia do Departamento de Cirurgia, Faculdade de Medicina de Jundiaí (FMJ), Jundiaí/SP.

\section{Endereço para correspondência:}

Jéssica Mayara Mesquita Ivanovs - R. Maestro Francisco Farina, № 55 Apto 103 Bloco B - Vila Progresso, Jundiaí-SP - CEP 13202-250. Tel.: (11) 97136-4575, e-mail: jessicamayara9@hotmail.com

\section{RESUMO:}

Introdução: Entender o desejo de participação de responsáveis cujo dependente será submetido ao ato anestésico - cirúrgico tem se tornado fundamental para tomada de decisões de alta qualidade. Informações baseadas em evidências, esclarecimento das opções de tratamento disponíveis e seus benefícios e malefícios e avaliação dos objetivos leva a um maior alinhamento entre a expectativa do paciente/responsável e a decisão final. Objetivo: Avaliar se há desejo de participação de pais e responsáveis nos cuidados anestésicos e perioperatorios de seus filhos que serão submetidos à anestesia no Hospital Universitário de Jundiaí. E secundariamente, analisar correlações entre o desejo de participação, com o grau de escolaridade dos pais e a idade da criança. Metodologia: Trata-se de um estudo observacional, transversal, onde no momento da consulta pré-anestésica os responsáveis de todas as crianças com idade até 12 anos que serão submetidas ao procedimento anestésico para realização de cirurgia serão convidados a responder dois questionários destinados a caracterizar o perfil sociodemográfico e a avaliar as preferências de pais ou responsáveis em relação aos cuidados perioperatórios de seus filhos.

Palavras-Chave: anestesia, participação dos pais, anestesia pediátrica, tomada de decisão compartilhada. 


\section{PREVALÊNCIA DE TRANSTORNOS MENTAIS COMUNS EM ESTUDANTES DE MEDICINA E SUA ASSOCIAÇÃO COM QUALIDADE DE VIDA E EMPATIA, UM ESTUDO PROSPECTIVO}

Mariana Berwerth Pereira ${ }^{1}$, Amanda Victória Casagrande ${ }^{1}$, Paula Villela Nunes².

1. Graduando do curso de Medicina; Faculdade de Medicina de Jundiaí

2. Professora adjunta da Disciplina de Psiquiatria do Departamento de Clínica Médica, Faculdade de Medicina de Jundiaí (FMJ), Jundiaí/SP.

\section{Endereço para correspondência:}

Mariana Berwerth Pereira - R. Zuferey, o 211 - Vila Progresso, Jundiaí-SP - CEP 13202-420. Tel.: (11) 999199566, e-mail: marianaberwerth@hotmail.com.

\section{RESUMO:}

Introdução: Transtornos mentais comuns (TMC) indicam problemas mentais não psicóticos que podem ter impacto socioeconômico. A qualidade de vida (QV) dos estudantes de medicina é questionada pela elevada carga horaria e pelas cobranças da profissão. Empatia é importante para área médica e possui relação com o cuidado ao paciente. Existem poucos estudos prospectivos que avaliam a prevalência de TMC, empatia e QV dos alunos de medicina. Objetivo: Avaliar prospectivamente a prevalência de TMC, empatia e qualidade de vida nos alunos da Faculdade de Medicina de Jundiaí nos anos de 2018 e 2019. Materiais e Métodos: Materiais e Métodos: Questionários auto administrados foram aplicados aos estudantes da Faculdade de Medicina de Jundiaí. Para avalição dos TMC foi utilizado SRQ-20, para QV, WHOQOL-bref e para empatia, Índice de Reatividade Interpessoal (IRI). Para análise das variáveis foram utilizados o teste Kruskal-Wallis e o teste qui-quadrado de Pearson e para analisar cada turma prospectivamente foram utilizados os testes de Mann-Whitney e qui-quadrado de Pearson. Resultados: $\mathrm{Na}$ análise prospectiva não foi encontrada diferença nas porcentagens de SRQ$20 \geq 7(p=0,900)$, entretanto, houve diminuição $(p=0,015)$ das médias de pontuação total da SRQ-20 de $2018(8,4 \pm 4,7)$ para $2019(8,3 \pm 4,6)$. Quanto a WHOQOL, nos subitens "ambiente" $(60,3 \pm 15,2$ para $71,3 \pm 13,4)$ e "relações sociais" $(53,0 \pm 24,1$ para $65,3 \pm 21,7)$ houve melhora $(p<0,001$ para ambos) nas médias de 2018 para 2019. Nos subintes "físico" e "psicológico" não houve diferença ( $p=0,151$ e $\mathrm{p}=0,166$ ). Quanto aos subitens da escala IRI de empatia, ao comparar a mesma amostra nos dois anos consecutivos de 2018 e 2019, foi possível encontrar um aumento em "perspectiva empática" $(p<0,001)$ de $2,5 \pm 0,6$ para $2,9 \pm 0,7$ e em "fantasia" $(p=0,047)$ de $2,3 \pm 0,9$ para $2,3 \pm 0,9$, respectivamente. Nos outros subitens "tomada de perspectiva" e "desconforto pessoal" não houve diferença entre 2018 e 2019 ( $p=0,184$ e $p=0,340$, respectivamente). Conclusão: A prevalência de alunos com pontuações acima da nota de corte (SRQ-20 $\geq 7$ ) para TMC não mudou ao longo de 1 ano, apesar da pontuação média ter diminuído. Ao longo de 1 ano a QV em seus subitens "ambiente" e "relações sociais" e a empatia nos subitens "perspectiva empática" e "fantasia" tiveram suas médias elevadas. Medidas de suporte aos estudantes de medicina devem ser implementadas afim de melhorar a saúde mental e promover uma vida com menos TMC. É possível melhorar a empatia e a QV dos alunos. Atividades que desenvolvem a empatia deveriam ser incentivadas aos estudantes, assim como a promoção para uma melhor QV.

Palavras-Chave: Estudantes de medicina, saúde mental, qualidade de vida, empatia. 


\section{SOROPREVALÊNCIA DA RUBÉOLA EM GESTANTES DE ALTO RISCO DA COORTE ZIKA JUNDIAÍ E ASSOCIAÇÃO COM A MICROCEFALIA}

Maria Eduarda Bueno Tabacchi Mazza1 ${ }^{1}$, Ana Luisa Marossi Justiniano², Saulo Duarte Passos ${ }^{3}$

1. Graduando do curso de Medicina; Faculdade de Medicina de Jundiaí

2. Graduando do curso de Medicina; Faculdade de Medicina de Jundiaí

3. Professor Titular da Disciplina de Pediatria do Departamento de Infectologia Pediátrica, Faculdade de Medicina de Jundiaí (FMJ), Jundiaí/SP.

\section{Endereço para correspondência:}

Maria Eduarda Bueno Tabacchi Mazza - R. Zuferey, o 211 - Vila Progresso, Jundiaí-SP - CEP 13202420. Tel.: (19) 991308460, e-mail: dudatabacchi@hotmail.com.

\section{RESUMO:}

Introdução: A rubéola é uma doença infecciosa causada pelo Vírus da Rubéola, cuja transmissão ocorre pelas vias respiratórias, através de secreções nasofaríngeas e possui, como manifestações mais comuns, mal estar, linfoadenomegalia, febres baixas, sintomas respiratórios e o aparecimento de pápulas eritematosas pelo corpo. Porém, é importante ressaltar que a rubéola também pode ser transmitida por via transplacentária, podendo trazer graves consequências para o concepto principalmente no primeiro trimestre de gestação, caracterizando a Síndrome da Rubéola Congênita (SRC). Atualmente, a SRC foi incluída entre as TORCH. Diante do aumento anormal de microcefalia no Brasil reportada pela OMS (Organização Mundial da Saúde) é de suma importância avaliar a prevalência da rubéola no cenário atual. Diante disso, o estudo de coorte Zika Jundiaí - Infecção Vertical pelo Zika, busca, por meio de um estudo prospectivo, analisar a prevalência da rubéola em gestantes de alto risco na Coorte Zika Jundiaí e relacionar tais dados com a incidência de microcefalia no recémnascido. Objetivo: Analisar a prevalência de rubéola em gestantes de alto risco na Coorte Zika Jundiaí e relacionar com a incidência de microcefalia no recém nascido. Materiais e Métodos: Para a realização do teste de rubéola, são usadas amostras de soro congeladas, coletadas das gestantes e recém nascidos participantes da Coorte Zika Jundiaí. O teste de rubéola é feito pelo método ELISA a partir das amostras sorológicas coletas. Resultados: Para as 532 análises de $\lg G$ das gestantes, obteve-se 134 resultados negativos para a presença do anticorpo e 398 resultados positivos. Já para os 540 resultados de IgM, obteve-se 539 amostras negativas e apenas 1 amostra positiva. Dos 168 dados referentes ao $\lg G$ nos recém nascidos, 57 tiveram resultado negativo e 111, positivo. Em relação ao $\operatorname{lgM}, 100 \%$ das amostras dos RNs obtiveram resultado negativo. Foram encontrados, 15 casos em que a gestante apresentou-se IgG positivo e o seu recém nascido, IgG negativo. Avaliando o desenvolvimento dos RNs com IgG positivo para o vírus da rubéola, nota-se que 13 obtiveram classificação de microcefalia ao nascimento. Conclusão: A frequência de $\lg G$ encontrado nas mães foi abaixo do número esperado pelo Ministério da Saúde. Não houve caso de IgM positivo observado no estudo. Das crianças com microcefalia, somente uma apresentou IgG positivo para Rubivirus. Para os casos discordantes entre gestante com IgG positivo e RN com IgG negativo, será feita avaliação de cada caso.

Palavras-Chave: rubéola, microcefalia, transmissão vertical. 


\title{
DESCOBERTA PRÉ-CLÍNICA E DESENVOLVIMENTO DA MILTEFOSINA ORAL PARA O TRATAMENTO DA LEISHMANIOSE VISCERAL
}

\author{
Débora de Paula Pita Pedro'1, Adriano Cappellazzo Coelho², Juliana Quero Reimão³.
}

1. Graduanda do curso de Medicina; Faculdade de Medicina de Jundiaí

2. Professor Adjunto da Disciplina de Parasitologia do Departamento de Biologia Animal da Universidade Estadual de Campinas (UNICAMP), Campinas/SP.

3. Professora Adjunta da Disciplina de Parasitologia do Departamento de Morfologia e Patologia Básica da Faculdade de Medicina de Jundiaí (FMJ), Jundiaí/SP.

\section{Endereço para correspondência:}

Juliana Quero Reimão - R. Francisco Teles, oo 250 - Vila Arens II, Jundiaí-SP - CEP 13202-550. Tel.: (11) 3395-2100, e-mail: juliana_reimao@yahoo.com.br.

\section{RESUMO:}

Introdução: A leishmaniose visceral (LV) é uma doença transmitida por insetos vetores e causada por protozoários intracelulares obrigatórios das espécies Leishmania donovani e Leishmania infantum, que provocam uma reação inflamatória persistente no organismo do hospedeiro. Intimamente relacionada com a pobreza, a LV acarreta elevada morbidade e representa um dos principais fardos à saúde pública nos países em desenvolvimento. A miltefosina (MF) é o primeiro fármaco de uso oral em fase de teste clínico e já registrado em alguns países para o tratamento da LV, sendo considerada crucial em programas de eliminação da doença. Tem-se observado, no entanto, um decréscimo em sua eficácia, o que impõe a descoberta de novos esquemas terapêuticos Objetivo: O presente estudo teve como objetivo revisar os aspectos farmacológicos pré-clínicos e clínicos mais relevantes da MF, seu mecanismo de ação e resistência contra Leishmania e fornecer uma visão geral desde sua descoberta até as publicações mais recentes e perspectivas para esse fármaco. Materiais e Métodos: PubMed e outras bases de dados científicos foram empregadas, usando-se os termos relacionados às palavras "leishmania", "leishmaniasis", "kala azar" e "miltefosine". Resultados: A MF é o único agente de administração oral reconhecido e aprovado para tratamento da LV. Este fármaco foi desenvolvido inicialmente para tratamento de câncer, mas seu desenvolvimento como agente anti-Leishmania se deu mediante uma colaboração firmada entre a companhia farmacêutica ASTA Medica (atual Zentaris) e o Programa Especial de Pesquisa e Treinamento em Doenças Tropicais da Organização Mundial da Saúde. O mecanismo de ação e a farmacodinâmica da MF ainda não são totalmente esclarecidos, mas seu uso é estritamente contraindicado durante a gestação devido ao seu potencial teratogênico, sendo mandatório o uso de métodos contraceptivos em mulheres em idade fértil durante o tratamento e nos meses subsequentes. Conclusão: Tem-se observado um aumento de casos refratários à MF e recidivas após seu uso, sugerindo a seleção de parasitos resistentes e impondo a necessidade de se pesquisar e desenvolver terapias combinadas. Apesar de suas limitações, a MF é um exemplo de sucesso em pesquisa e desenvolvimento para uma Doença Tropical Negligenciada.

Palavras-Chave: Miltefosina, leishmaniose visceral, agentes antiparasitários. 


\title{
UTILIZAÇÃO DE MEMBRANA DE QUITOSANA E NANOTUBOS DE CARBONO ASSOCIADOS A LASERTERAPIA PARA O TRATAMENTO DE LESÕES ÓSSEAS EM FÊMUR DE RATOS
}

\author{
Kudo $\mathrm{MHM}^{1}$, Fernandes JFR², Silva $\mathrm{SK}^{3}$, Cunha $\mathrm{MR}^{4}$
}

1. Graduando Mateus Hissashi Matsumoto kudo do curso de Medicina; Faculdade de Medicina de Jundiaí (FMJ), Jundiaí/SP.

2. Colaborador José Francisco Rebello Fernandes, aluno de Medicina da Faculdade de Medicina de Jundiaí (FMJ), Jundiaí/SP.

3. Colaboradora Samantha Ketelyn Silva, Aluna do programa de Pós-Graduação - Doutorado FMJ, Faculdade de Medicina de Jundiaí (FMJ), Jundiaí/SP.

4. Professor Doutor Marcelo Rodrigues da Cunha da Disciplina de Anatomia do Departamento de Morfologia e Patologia Básica da Faculdade de Medicina de Jundiaí (FMJ), Jundiaí/SP.

\section{Endereço para correspondência:}

Nome do Autor - Mateus Hissashi Matsumoto Kudo. Rua Zuferey, № 183, bloco 02, apto 104 - Bairro Pitangueiras, Jundiaí-SP - CEP 13202-420. Tel:(18)98159-7103, e-mail: mateushmk@hotmail.com

\section{RESUMO:}

Introdução: Atualmente, o índice de fraturas ósseas relacionadas a trauma, tumores e outras patologias vem crescendo consideravelmente. Deste modo, diversas pesquisas surgem com o intuito de melhorar ou otimizar o processo de regeneração óssea, através do desenvolvimento de biomateriais para atuar como suporte adequado para recuperação efetiva. Dentre os biomateriais, destacam-se a membrana de quitosana e os nanotubos de carbono. $O$ uso do laser de baixa intensidade também é indicado como auxílio no processo de reparo ósseo, por seu efeito bioestimulador. Objetivo: Avaliar a regeneração óssea através do uso do laser associado aos implantes de biomateriais a base de quitosana e nanotubos de carbono. Materiais e Métodos: Foram utilizados 15 ratos Wistar machos, distribuídos: (G1) fratura experimental no fêmur esquerdo sem preenchimento (Controle), (G2) fratura experimental + laser, (G3) fratura experimental + membrana de quitosana + nanotubos e (G4) fratura experimental + quitosana + nanotubos + laser. Após 5 semanas foi realizada a morte indolor induzida, seguido das análises macroscópica, radiológica, histomorfométrica e estatística. Resultados: Nas análises macroscópicas e radiológicas observou-se biocompatibilidade e contorno da falha óssea bem definida. Os resultados histomorfométricos apontam uma maior formação óssea ao grupo QN (G3) de $64 \%$, seguido de $62 \%$ para o grupo Laser (G2) e $55 \%$ para o grupo QN-Laser (G4) todos estes superiores a formação ocorrida no grupo controle de $42 \%$. Conclusão: Os animais pertencentes aos grupos com implantes obtiveram bons resultados em relação à neoformação óssea e houve biocompatibilidade dos materiais enxertados na área da lesão. $O$ laser possui efeito benéfico mesmo quando utilizado individualmente, apresentando bom volume ósseo local.

Palavras-Chave: Quitosana, nanotubo de carbono, regeneração óssea, lasers. 